\title{
The role of interdisciplinary research team in the impact of health apps in health and computer science publications: a systematic review
}

\author{
Guillermo Molina Recio ${ }^{1 \dagger}$, Laura García-Hernández ${ }^{2^{*}}$, Rafael Molina Luque ${ }^{1 \dagger}$ and Lorenzo Salas-Morera ${ }^{2 \dagger}$
}

From 3rd International Work-Conference on Bioinformatics and Biomedical Engineering-IWBBIO 2015 Grenada, Spain. 15-17 April 2015

\section{${ }^{*}$ Correspondence:}

ir1gahel@uco.es

†Guillermo Molina Recio,

Laura García-Hernández,

Rafael Molina Luque and

Lorenzo Salas-Morera

contributed equally to this

work

${ }^{2}$ Area of Project Engineering,

University of Córdoba,

Córdoba, Spain

Full list of author information

is available at the end of the

article

\begin{abstract}
Background: Several studies have estimated the potential economic and social impact of the mHealth development. Considering the latest study by Institute for Healthcare Informatics, more than 165.000 apps of health and medicine are offered including all the stores from different platforms. Thus, the global mHealth market was an estimated $\$ 10.5$ billion in 2014 and is expected to grow 33.5 percent annually between 2015 and 2020s. In fact, apps of Health have become the third-fastest growing category, only after games and utilities.
\end{abstract}

Methods: This study aims to identify, study and evaluate the role of interdisciplinary research teams in the development of articles and applications in the field of mHealth. It also aims to evaluate the impact that the development of mHealth has had on the health and computer science field, through the study of publications in specific databases for each area which have been published until nowadays.

Results: Interdisciplinary nature is strongly connected to the scientific quality of the journal in which the work is published. This way, there are significant differences in those works that are made up by an interdisciplinary research team because of they achieve to publish in journals with higher quartiles. There are already studies that warn of methodological deficits in some studies in mHealth, low accuracy and no reproducibility. Studies of low precision and poor reproducibility, coupled with the low evidence, provide low degrees of recommendation of the interventions targeted and therefore low applicability.

Conclusions: From the evidence of this study, working in interdisciplinary groups from different areas greatly enhances the quality of research work as well as the quality of the publications derived from its results.

\section{Background}

Several studies have estimated the potential economic and social impact of the mHealth development. mHealth is an abbreviation for mobile health, a term used for the practice 
of medicine and public health supported by mobile devices. According to WHO [1], nearly $90 \%$ of the world population could benefit from the opportunities offered by mobile technologies and with a relatively low cost. Considering the latest study by Institute for Healthcare Informatics (IMS) [2], more than 165.000 apps of health and medicine are offered including all the stores from different platforms. Thus, the global mHealth market was an estimated $\$ 10.5$ billion in 2014 and is expected to grow 33.5 percent annually between 2015 and 2020s [3].

Also, the IMS Institute indicates that $70 \%$ of health apps is focused on general population, offering tools to reach and maintain wellness and to improve physical activity. The remaining $30 \%$, were designed to more concrete areas such as professionals or people affected by specific diseases.

Despite this situation, it is important to note that more than $50 \%$ of the available apps received less than 500 downloads and only five of them comprise $15 \%$ of all those in the health category. The IMS attributed this situation to different causes, which include: poor quality in many of them, the lack of guidance on the usefulness of the app and a low level of support from health professionals.

However, it is well-known that health apps, solving the problems detailed above, could represent a very useful tool for monitoring chronic diseases will account for $65 \%$ of the global market for mHealth in 2017 [3].

This fact will represent revenue of 15.000 million dollars. The pathologies with a higher potential to increase business are in order: diabetes and cardiovascular disease. They will also play an important role related to diagnostic services (they will reach $15 \%$ and will generate 3.400 million of dollars) and medical treatments (10\% of the market and revenues of 2.300 million). By the other hand, it is estimated that business will increase from 4.500 million in 2013, to 23.000 million in 2017. Continents with largest market share are, in descending order, Europe and Asia (30 \%), United States of America and Canada (28 \%) [3].

However, we do not know if the apps available to the population are based on scientific knowledge and therefore, it is difficult to assess the real impact of this spectacular development on the health of populations. On the other hand, we do not know how the great spread of the phenomenon of Health 2.0 (that is a term presented in the mid-2000s, as the subset of health technologies mirroring the wider Web 2.0 movement, offering possibilities for changing health care which started with the introduction of eHealth following the emergence of the World Wide Web $[4,5]$ ) that is reaching the scientific field (medical or computer), which should occur in parallel in order to offer products that positively affect the health of citizens.

Therefore, this study aims to identify, study and evaluate the role of interdisciplinary research teams in the development of articles and applications in the field of mHealth and the impact that the development of mHealth has had on the health and computer science field, through the study of publications and the composition of the research teams in specific databases for each area, which have been published until nowadays. According to Yadros et al. [6] interdisciplinary research seems to be a supplier of creative and innovative approaches. It is able to produce new lines of research and renew scientific field. In this sense, the justification of using interdisciplinary research is thus particularly strong and crucial in scientific programmes addressing grand societal issues or challenges that require an holistic approach including biological, physical and social factors. 


\section{Methods}

This work is extended and based on the previous work [7]. A systematic review was conducted in two stages during November 2014. The first one was focused on locating papers available in databases from Health Sciences. After this step, we repeat the search but in the Computer Science field because we wanted to find the different penetration in each area. As recommended in the PRISMA Statement [8] for systematic reviews. The PRISMA Statement consists of a 27-item checklist and a four-phase flow diagram. The aim of the PRISMA Statement is to help authors improve the reporting of systematic reviews and meta-analyses. We describe the search strategy and the number of papers located, discarded and finally selected for review using a for-phase flow diagram. In the first stage, we have consulted the PubMed database. We used "mHealth" and "mHealth AND app" terms as search strategies. Finally 79 items were selected for reviewing (see Fig. 1). We also consulted "Science Direct" and "Scopus" using "mHealth" but reducing the search to "Computer Science" area. Having initially located 375 publications, only 27 were chosen for our study (see Fig. 2). Thus, a total of 106 items were reviewed. The impact factor of the journals that published the papers selected was consulted using the journal citation report from web of science (WoS). Since this impact factor usually varies for each year, we took the corresponding to the year when the article was published.

As noted previously, the execution of this work has been carried out by means of the recommendations given by the PRISMA [8] statement. So, this work includes a study through the following information:

- The summaries and results of all reviewed papers after performing his complete reading.

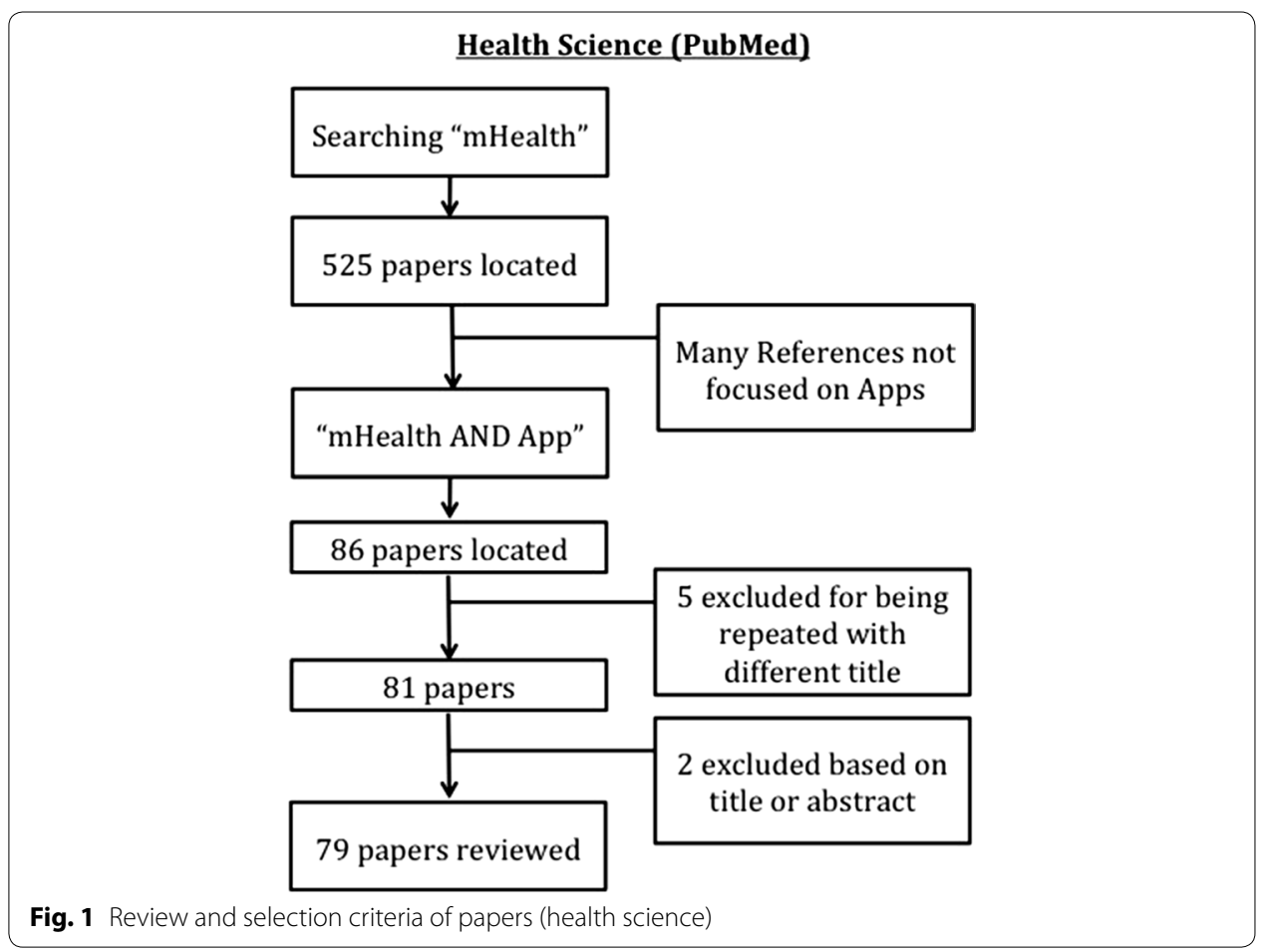




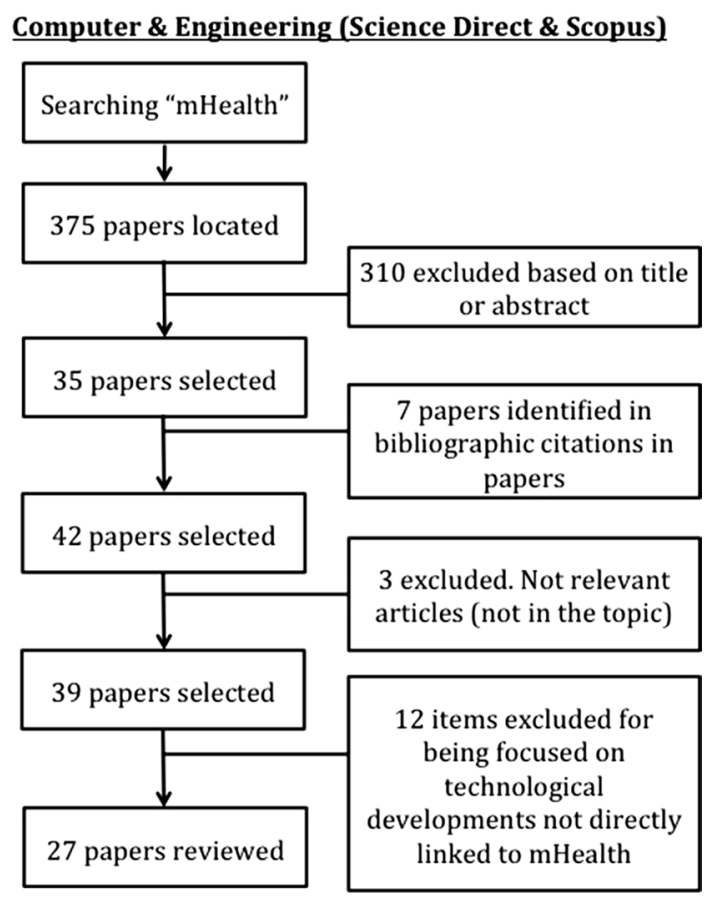

Fig. 2 Review and selection criteria of papers (computer science)

- The departments that participate in the development of the works and their categorization for subsequent statistical analysis.

This last categorization has been performed including the departments in ten large groups, which are: 'Research Center', 'Nursing and other health professionals,' 'Engineering and Technology', 'Finance and Statistics', 'General Medicine and Specialties', 'Agencies and Institutions,' 'Health,' 'Health Care and Community', 'Physiotherapy Associates', 'Pharmacy and Associates'.

In order to analyze and evaluate the impact of health apps in health and computer science publications in a precise way, additional features which are not used to be considered into systematic reviews, have been included in this study. All the information taken into account has been clustered into two main categories:

1. Publication characteristics:

- Journal name.

- Type of journal (According to 22 categories taken from ISI Web of Knowledge).

- Journal ranking (quartile).

- Journal impact factor.

- Article publication date.

- Type of study.

- Number of received citations. 
2. Interdisciplinary nature:

- Departments working on the contribution.

The evaluation of the last item (interdisciplinary nature) has been performed using the Rao-Stirling index as explained by Rafolds and Meyer [9], among others. Interdisciplinary research has been defined as a mode of research that integrates techniques, tools, and/or theories from two or more disciplines to advance fundamental understanding or to solve problems whose solutions are beyond the scope of a single discipline or area of research practice [10]. The advantage of the Rao-Stirling measure is that it takes into account the distribution of references across disciplinary categories on journals in the WoS for 220 WoS categories or subject categories (SC) and also considers how cognitively distant these categories are.

For statistical analysis of the data we have used own descriptive statistics (frequency tables, measures of central tendency and dispersion, Pearson correlation coefficient as well as graphic representation) and analytical techniques, using as evidence contrast hypothesis Chi square, $\mathrm{t}$ Student, ANOVA and Kruskal-Wallis as non-parametric version. Processing and analysis of data was performed using the SPSS version 22.0.0 [11].

\section{Results and discussion}

A brief summary of the main features, topics and contents in the reviewed papers is shown in Tables 1 and 2. We found papers focused on mHealth in 51 different journals, being most of them (68.6 \%) indexed in the ISI web of Knowledge. The higher proportion of papers published in journal indexed in JCR, is located in four WoS categories: medical informatics (17.9\%), Healthcare Sciences \& Services (12.8\%), computer science interdisciplinary applications (11.1\%) and mathematical and computational biology (8.5\%), showing a great concern about developing mHealth research in two fields of ISI that we think that must be strongly linked to this topic: clinical medicine and computer science. Taking into account not indexed journals, we found same development patterns, because most of the researches belong to different departments and institutions, including professionals from health and computer science. This fact could be explained by the concentration of articles in just three journals, journal of medical internet research mHealth and uHealth, (JMU) containing $21.7 \%$ of the published papers, journal of medical internet research (JMIR), covering $7.5 \%$ and international journal of medical informatics, reaching $4.7 \%$ papers. Thus, for example, journal of medical internet research is classified by journal citation report (JCR) into several categories ("Health Care Sciences \& Services" and "Medical Informatics") and the international journal of medical informatics is listed by JCR into three categories, the two previously mentioned, as well as in "Computer Science, Information Systems" that clearly belongs to a non-health area. Another important result is the great impact factor of these publications. This way, in any category where they could be classified of these two journals belong to the first quartile, excepting JMU which is not indexed because it was created in 2013 like an spin-off from JMIR. This may also explain that the average impact factor of the found publications was $1.54( \pm 1898)$ including all the papers, and $3.0248( \pm 1.6014)$ if we select just the papers published in indexed journals. Moreover, $27.4 \%$ of the articles are located in first quartile journals, $13.2 \%$ in the second, $7.5 \%$ in the third and $2.8 \%$ in the fourth 


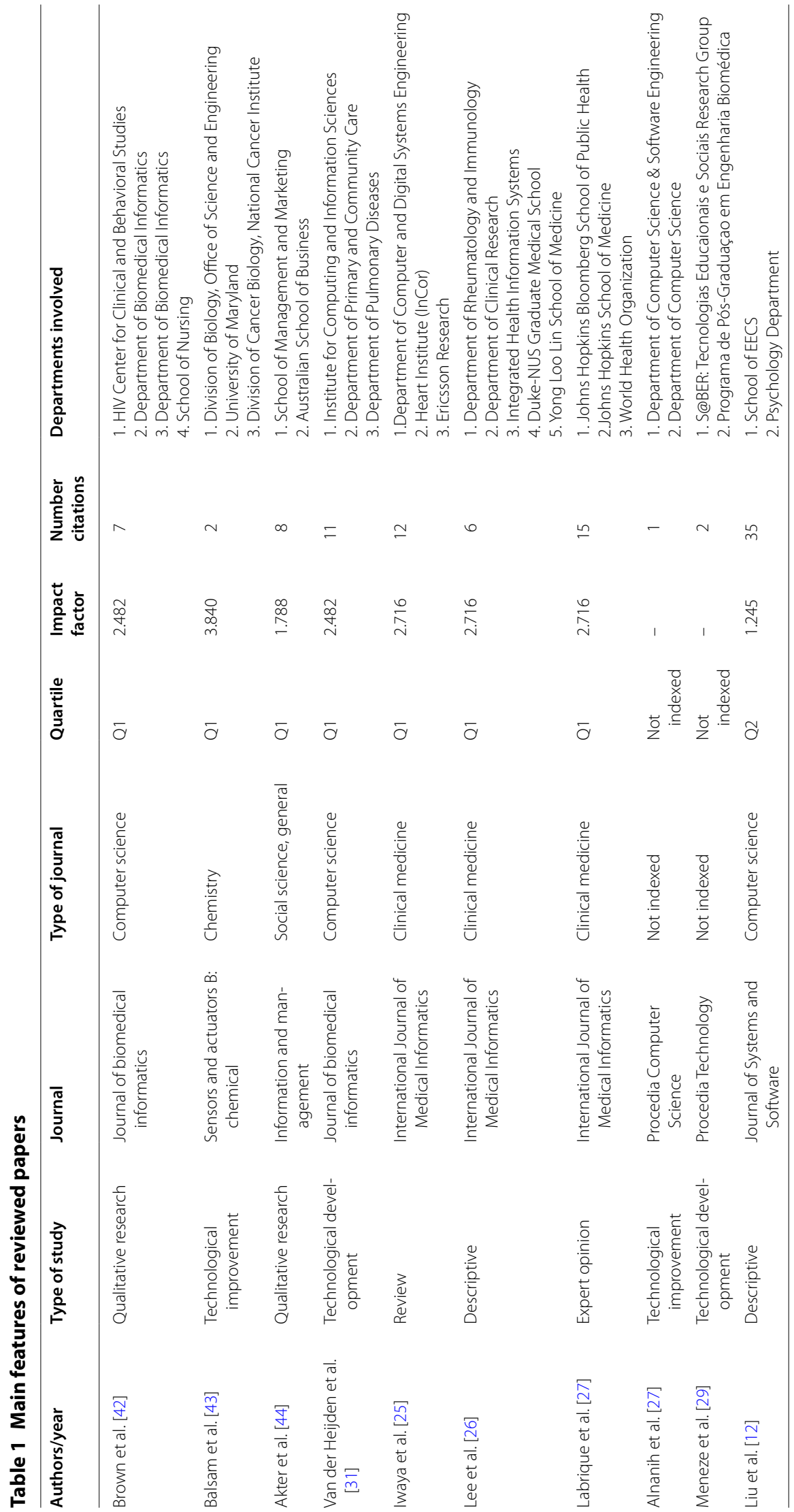




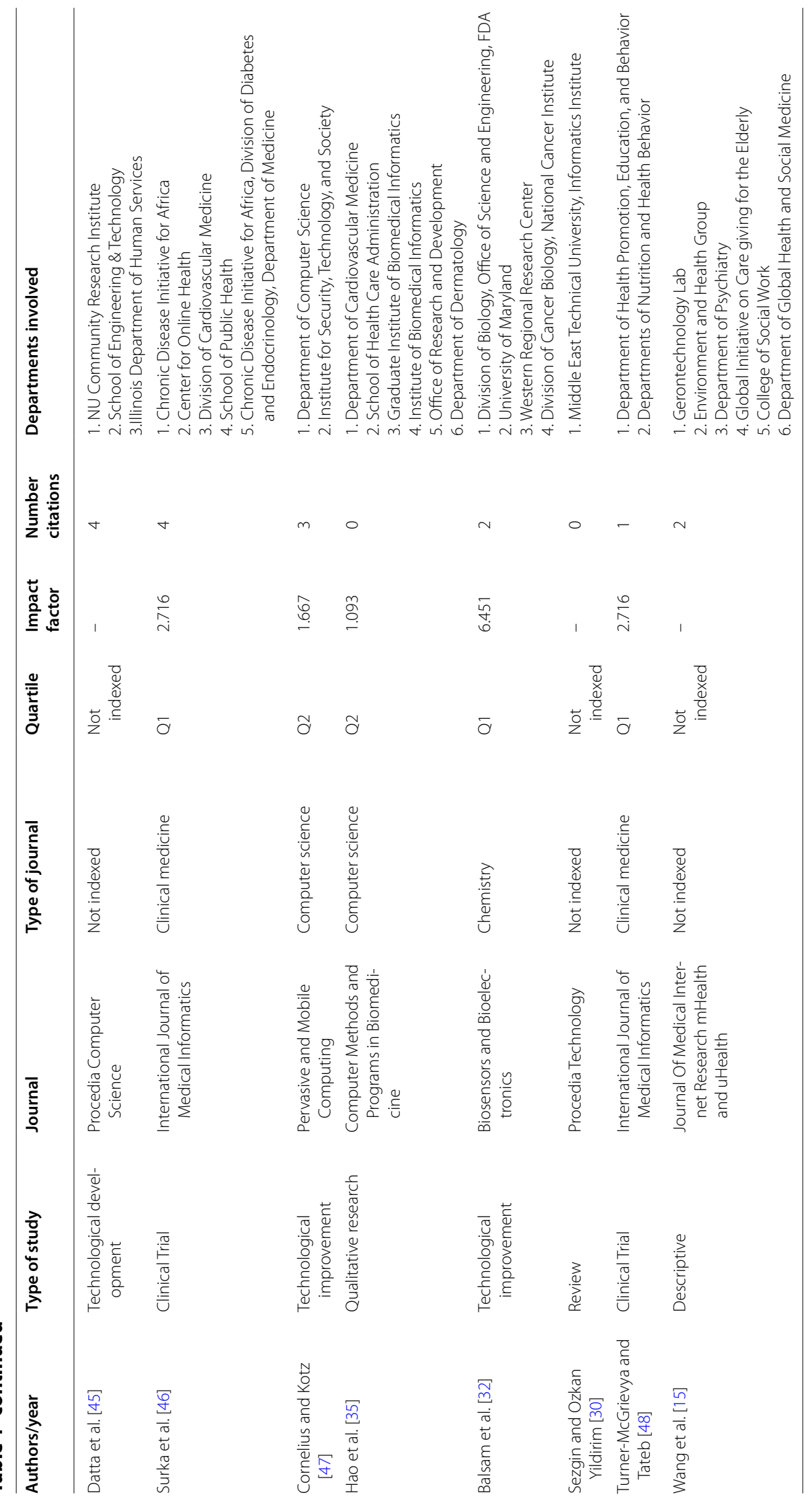




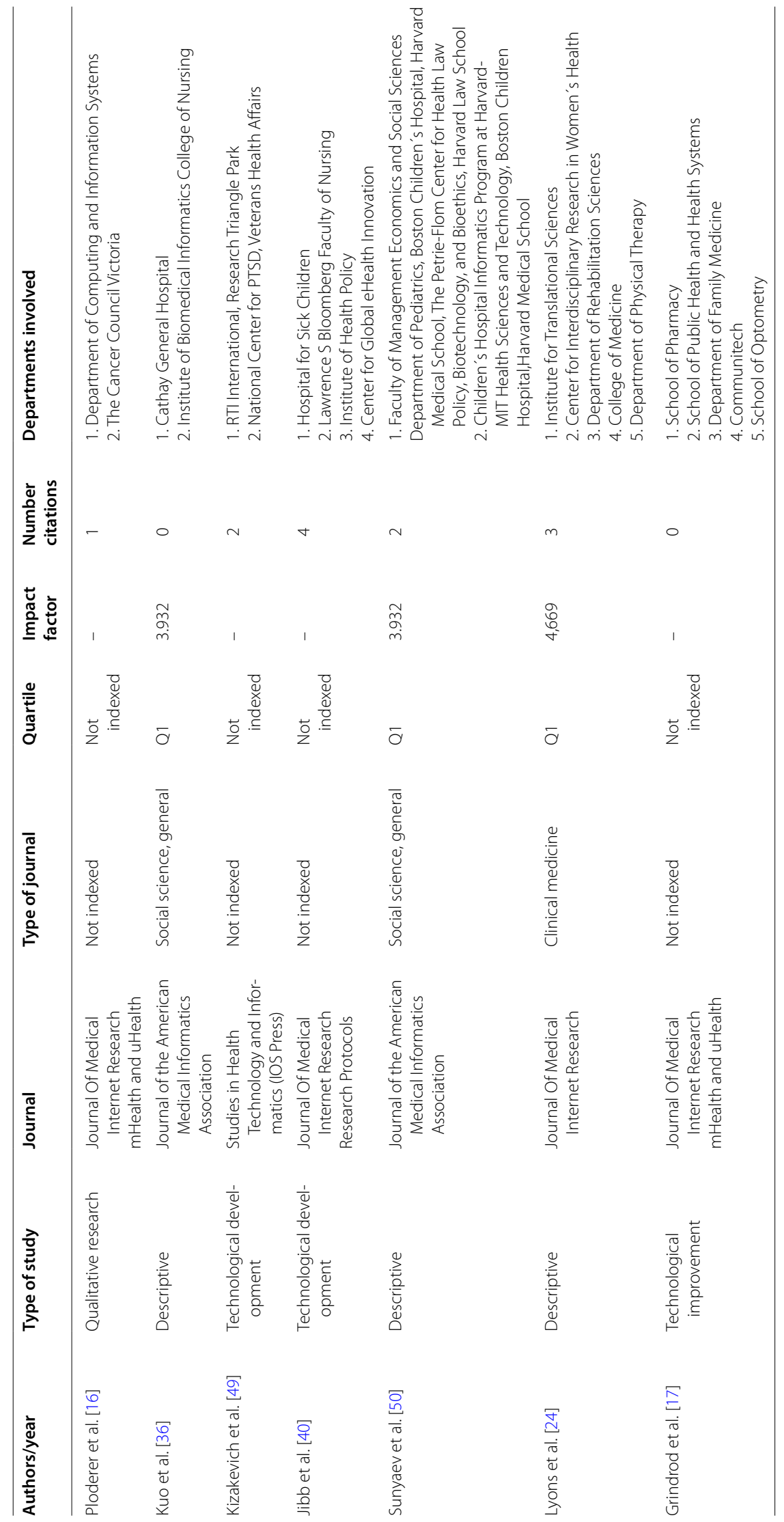




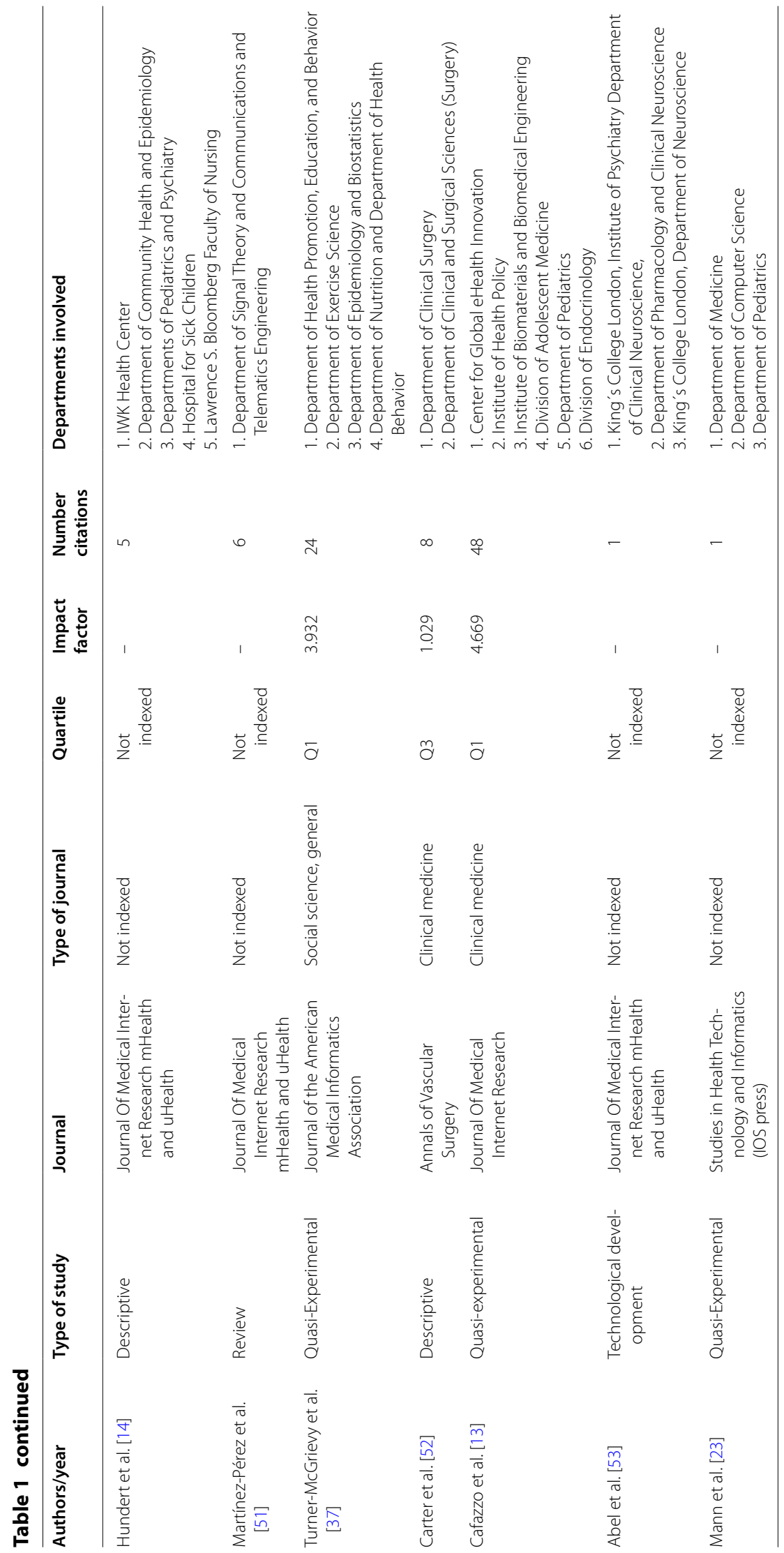




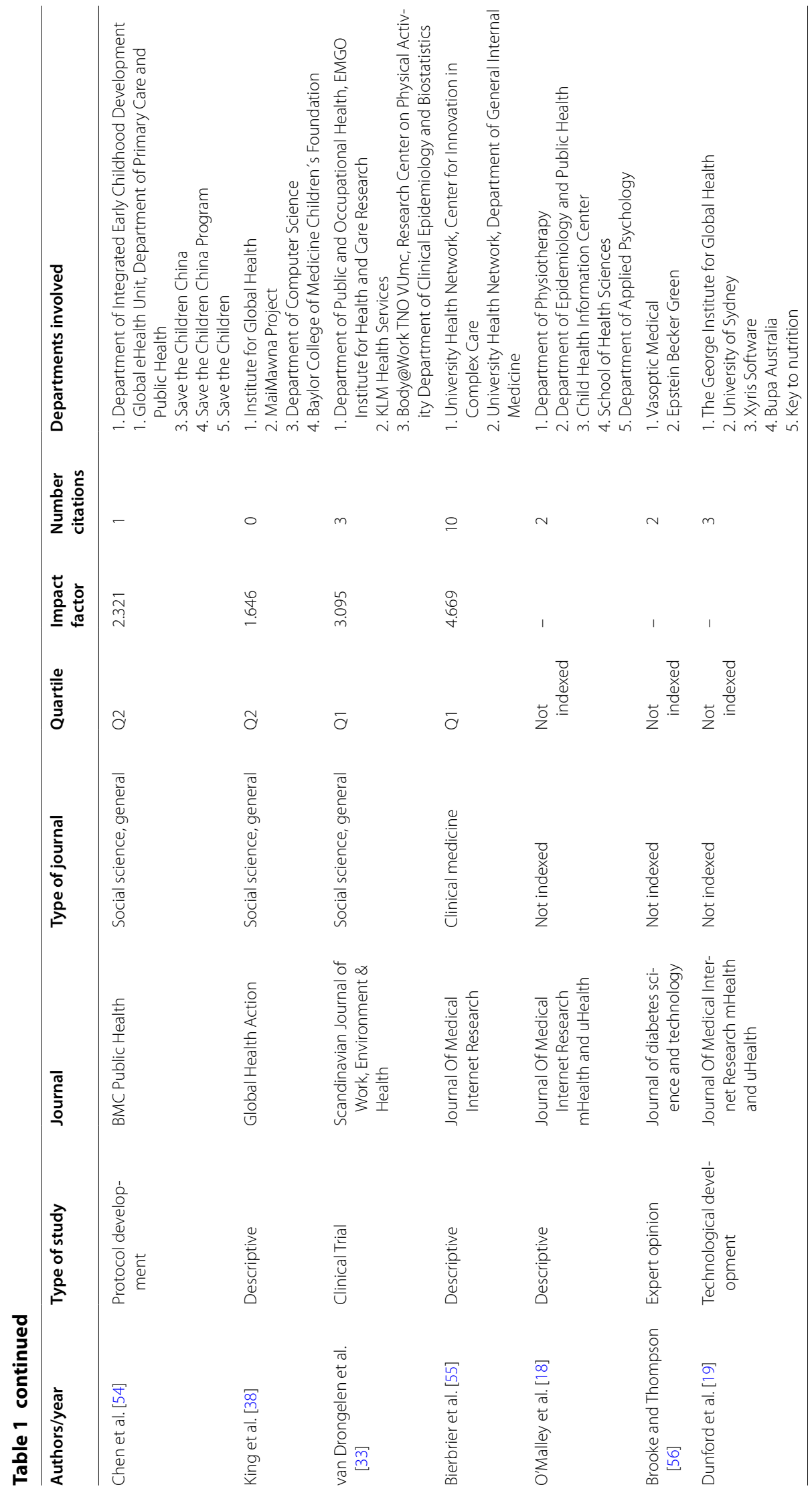




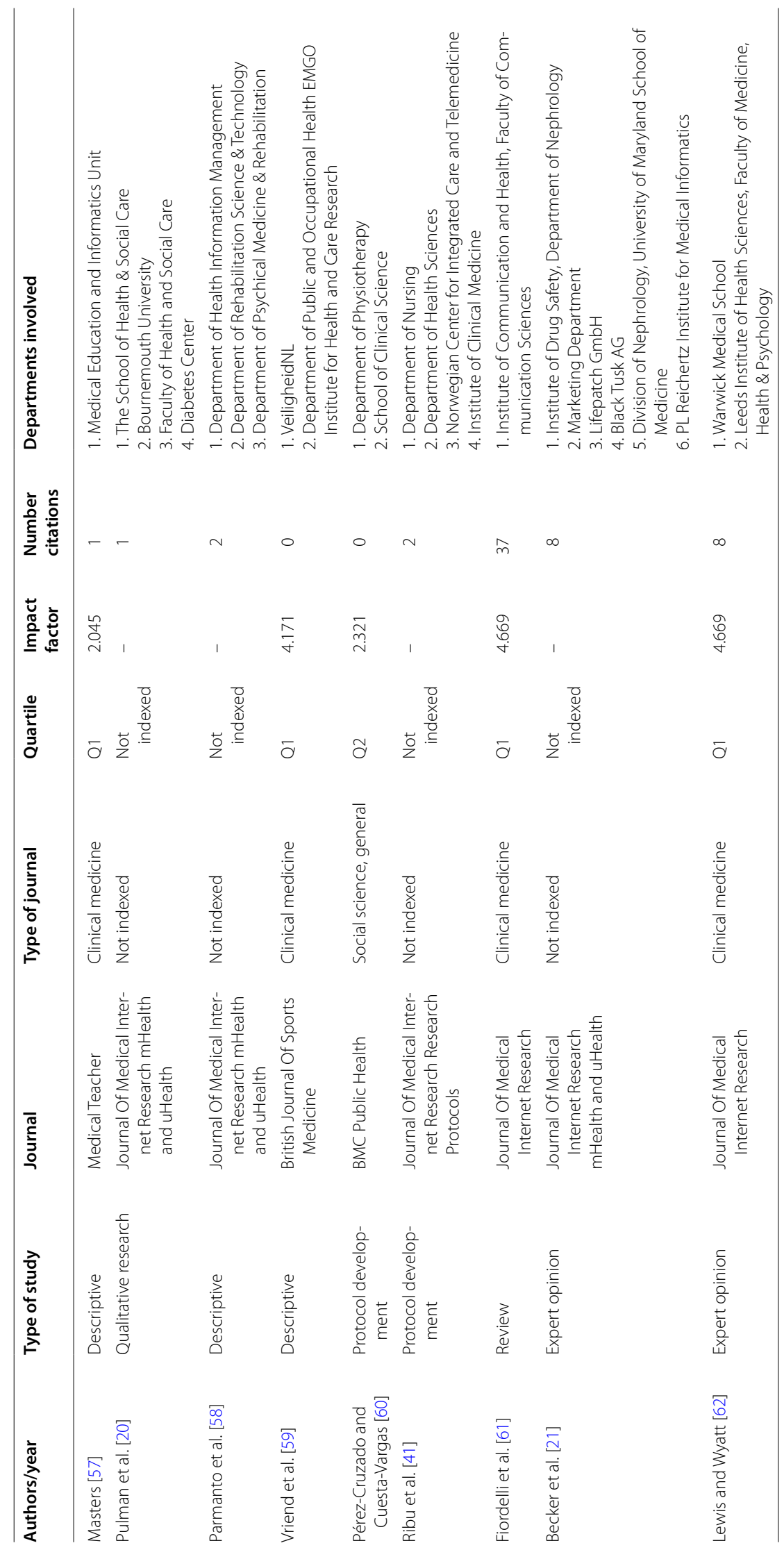




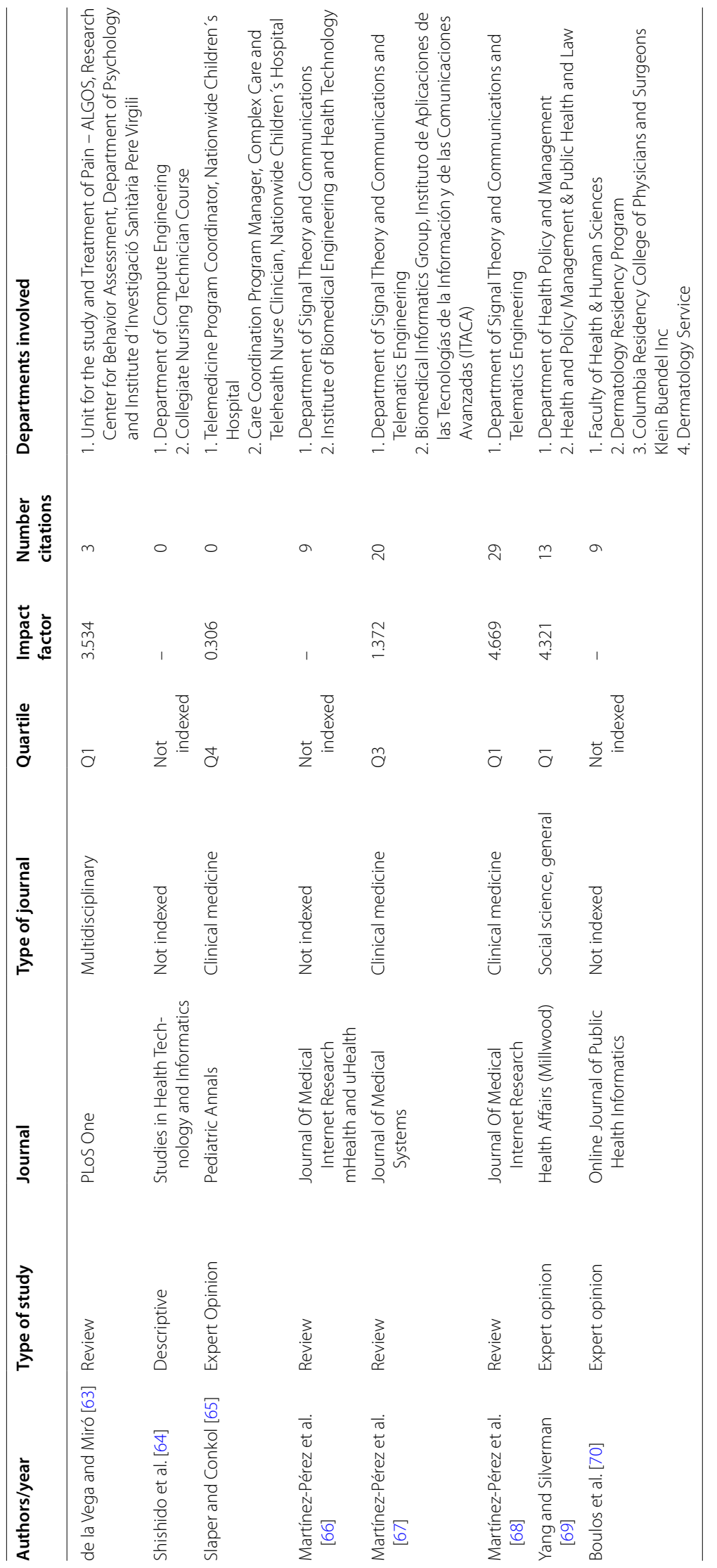




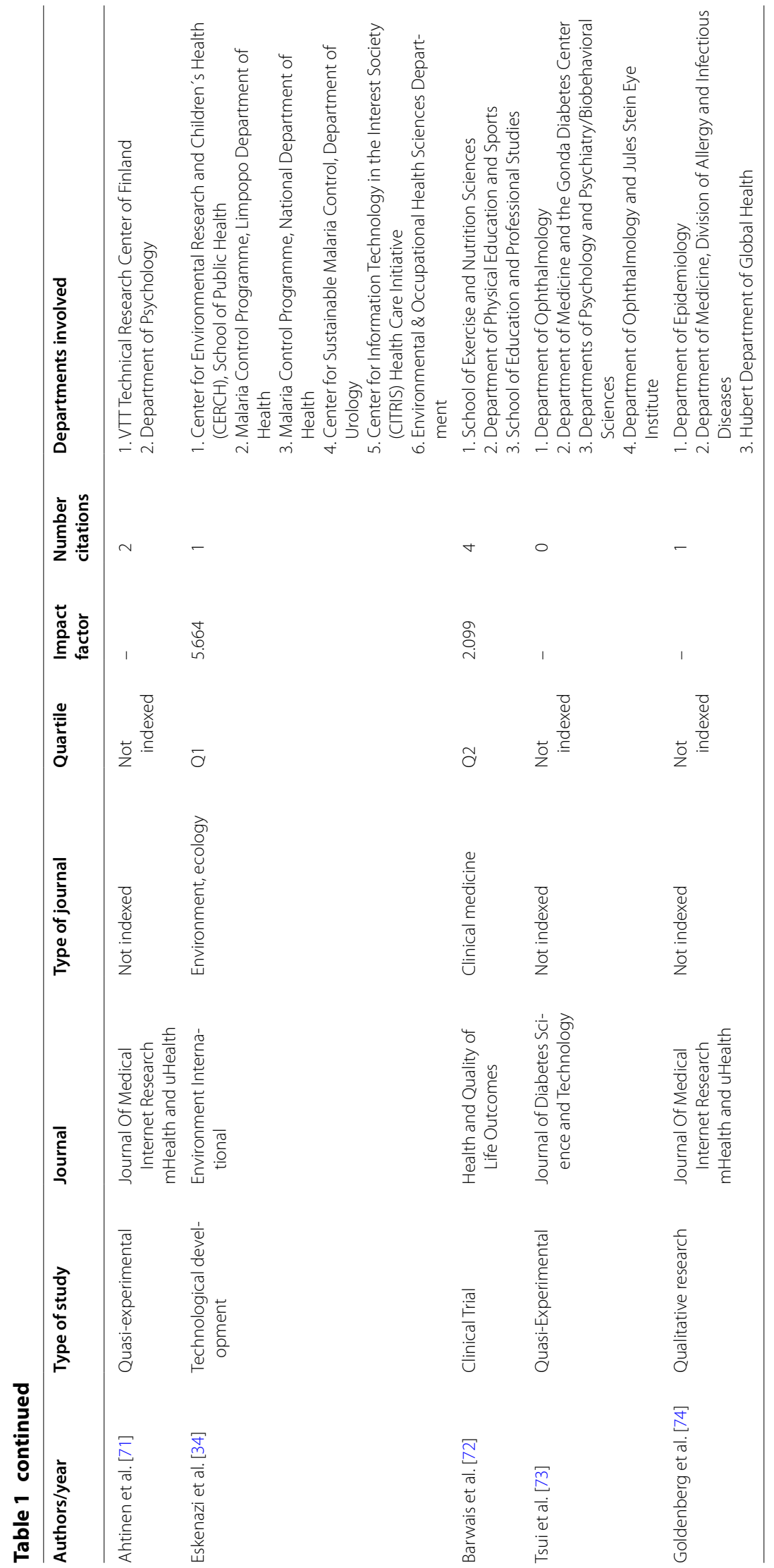




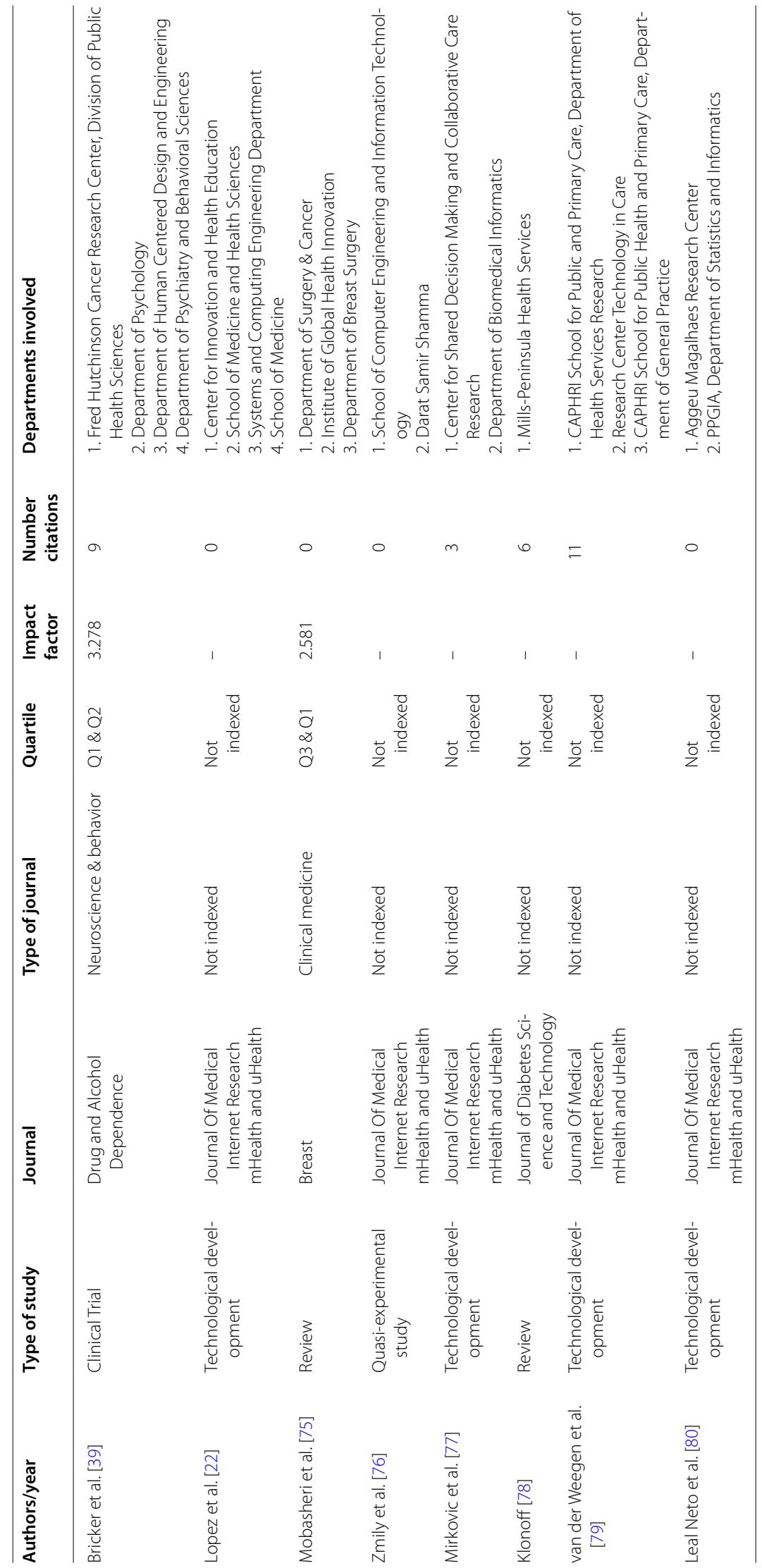




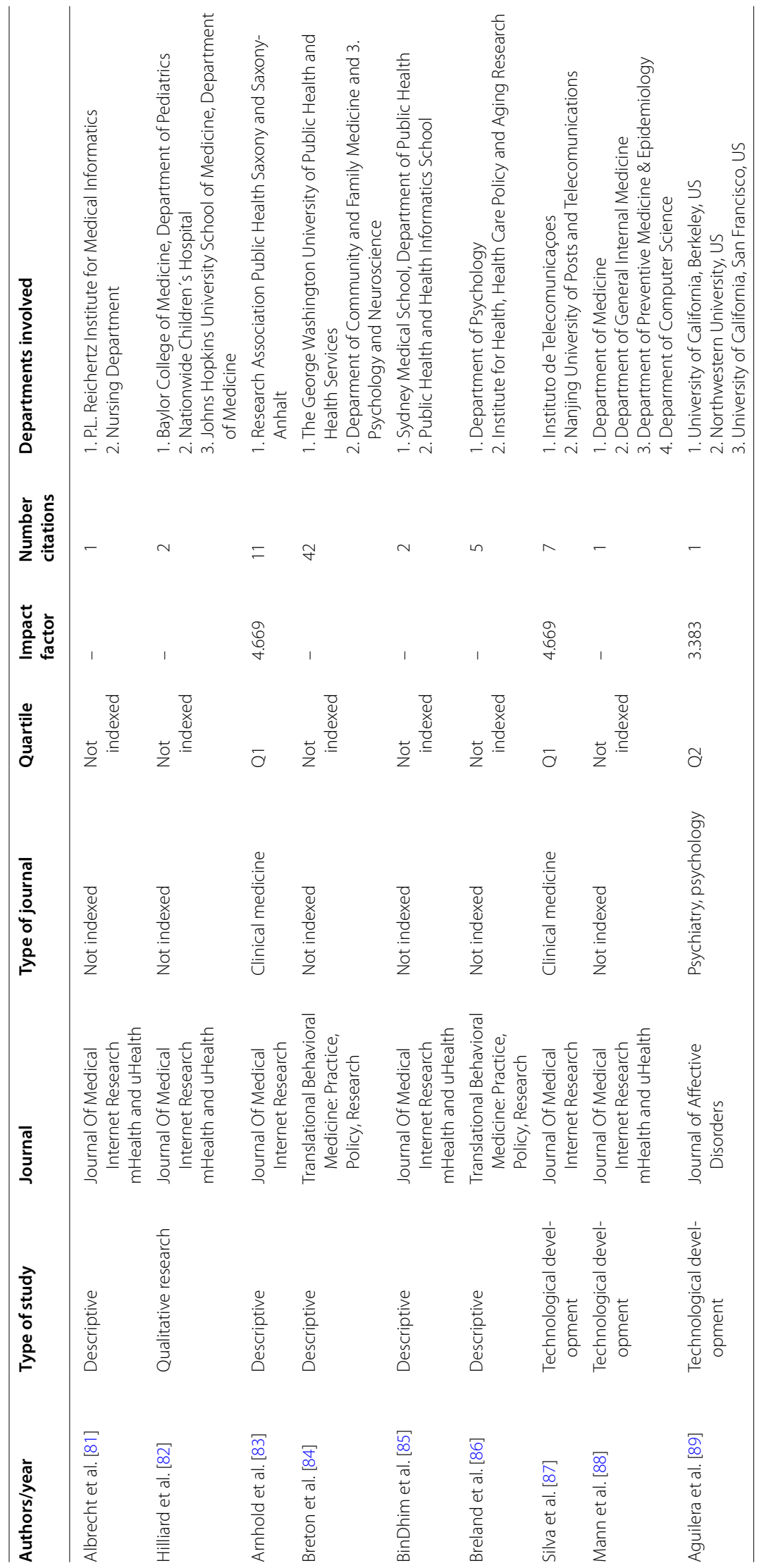




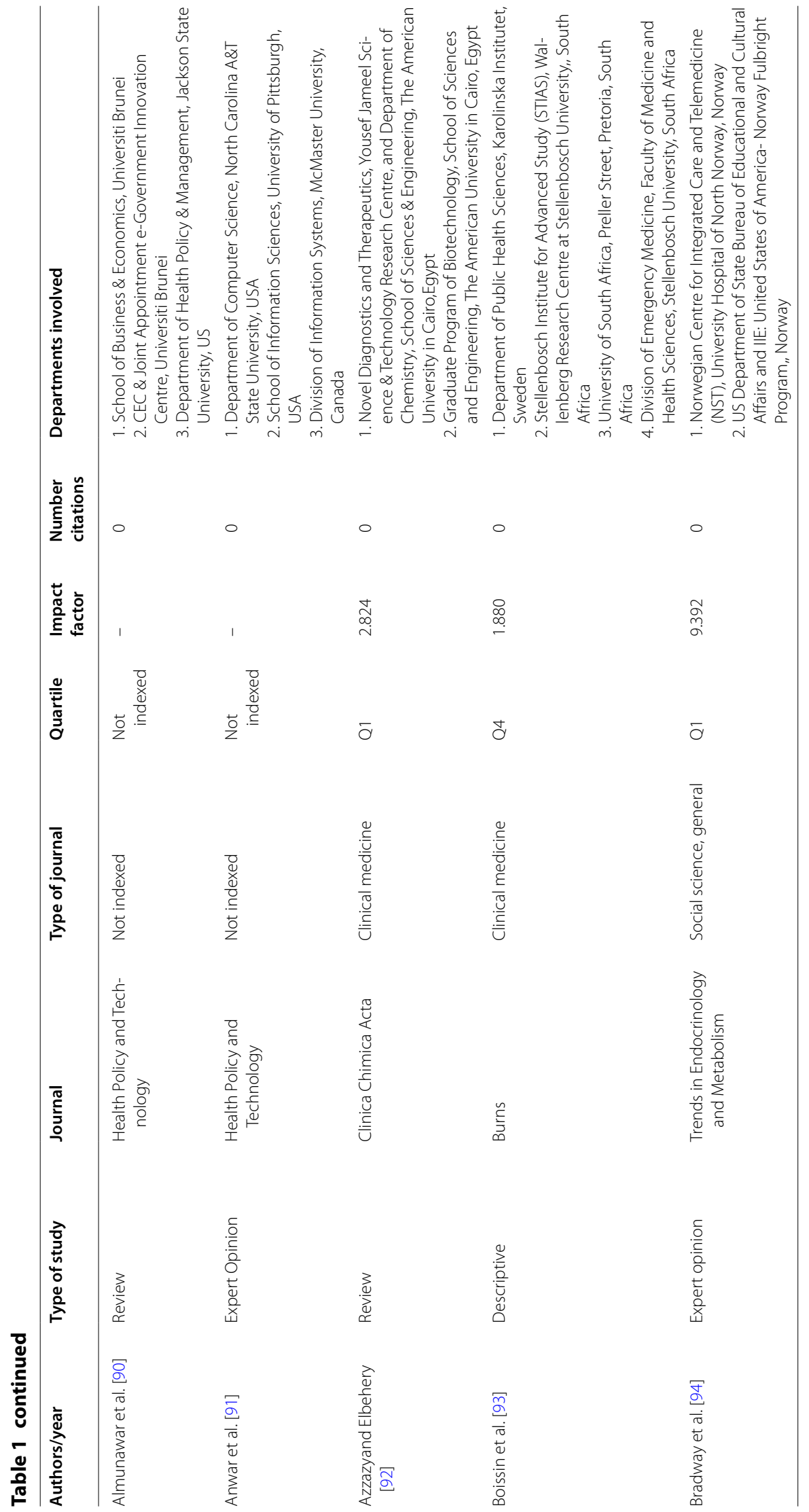




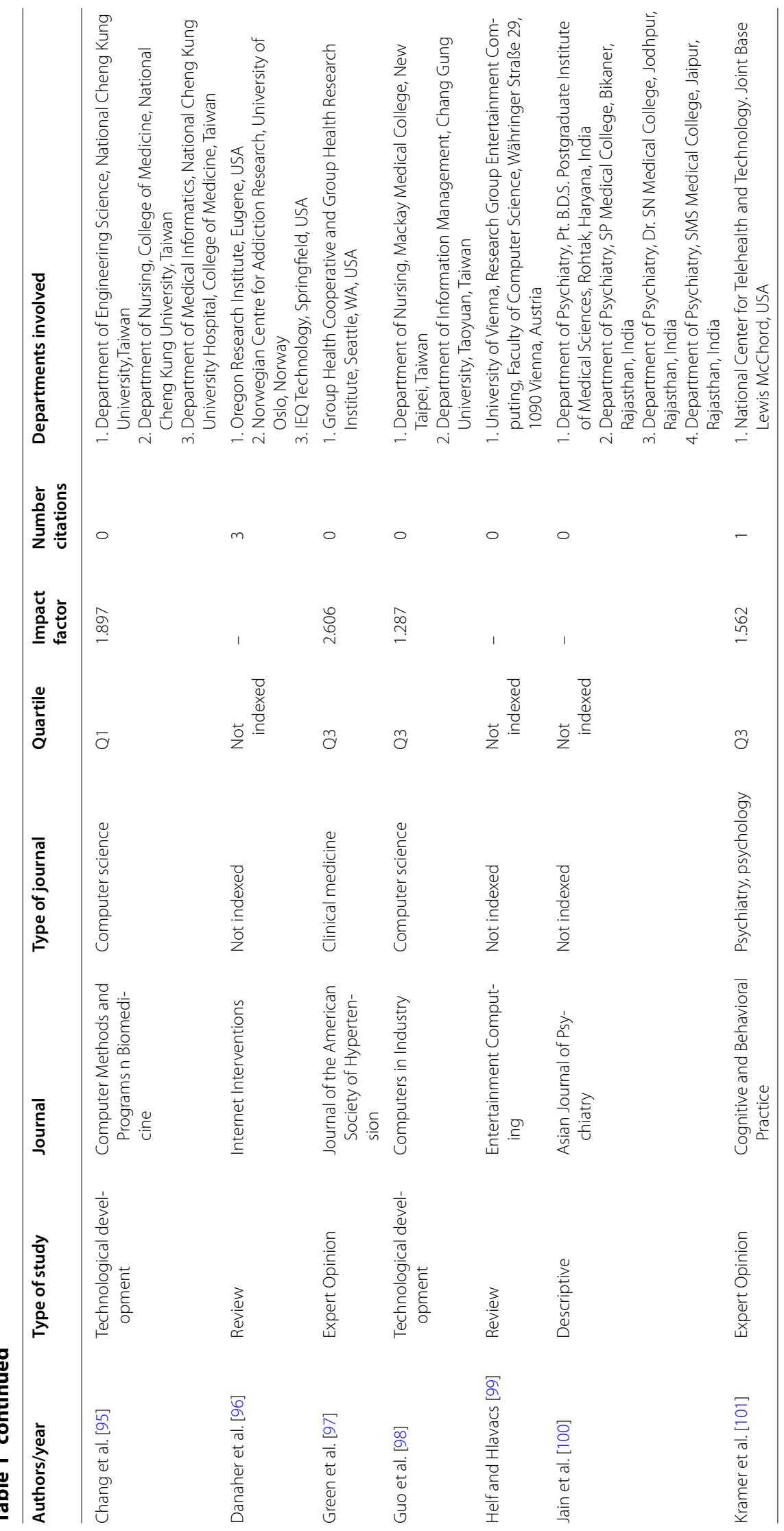




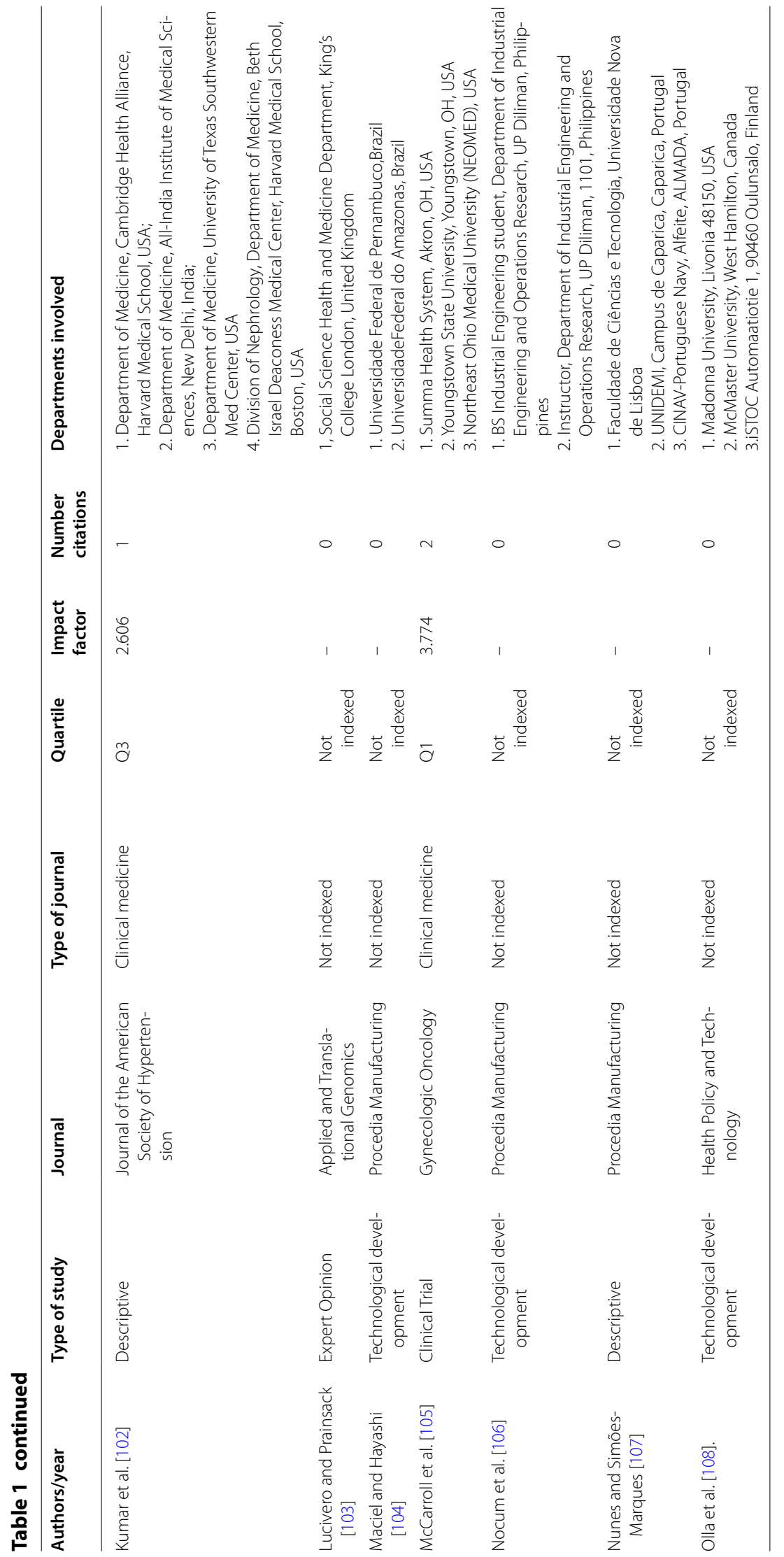




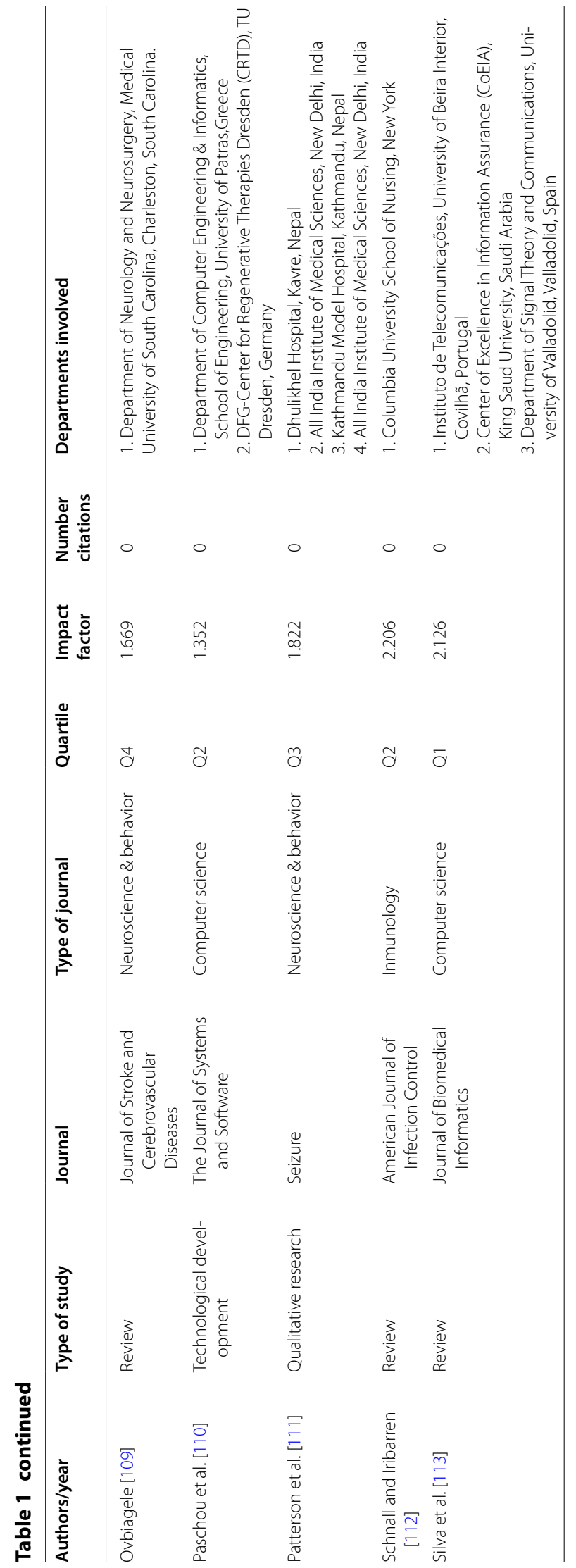




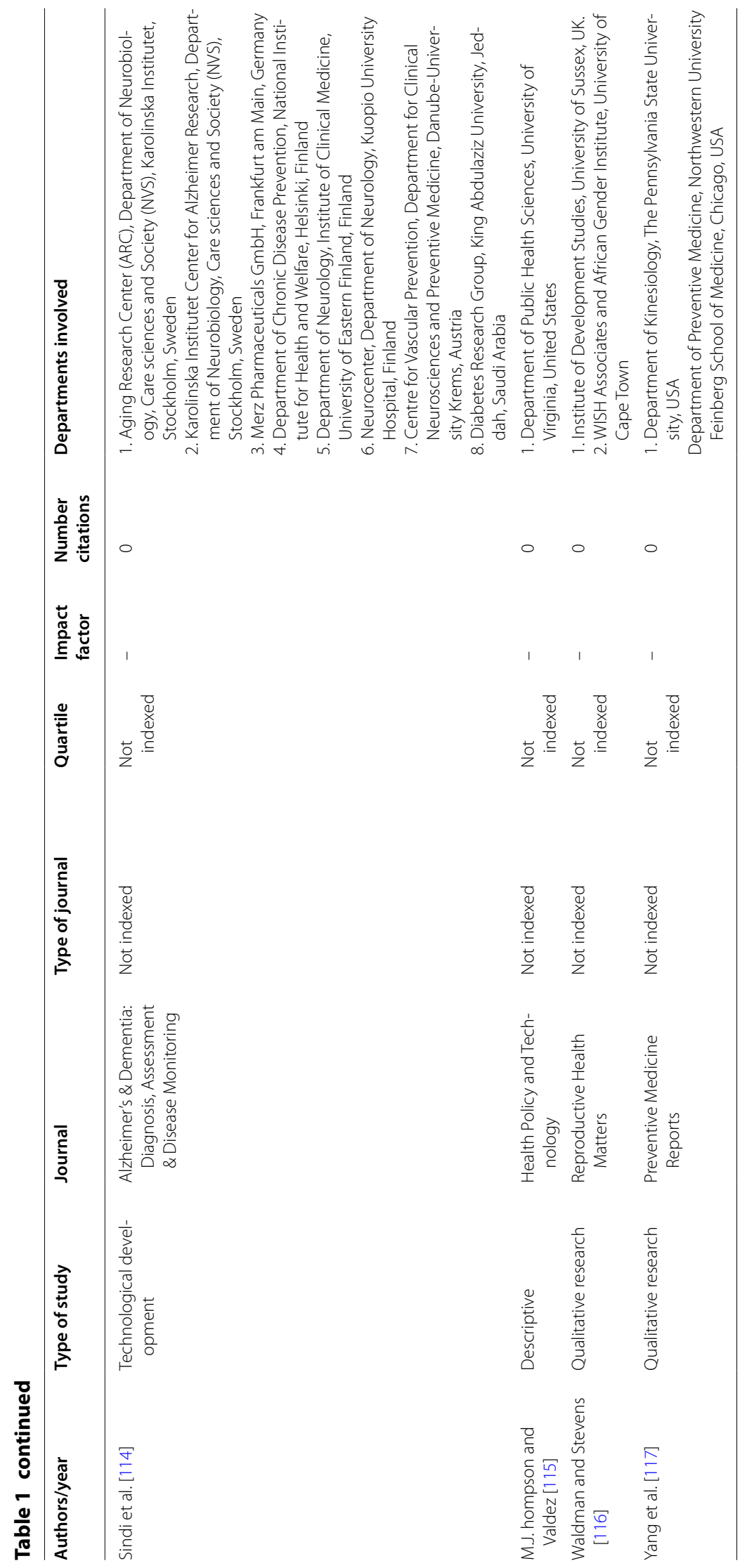


Table 2 Main results and conclusions of reviewed papers

Paper
Paper 1: Assessment of the health
IT usability evaluation model
(Health-ITUEM) for evaluat-
ing mobile health (mHealth)
technology
Paper 2: Capillary array waveguide
amplified fluorescence detector
for mHealth
Paper 3: Development and
validation of an instrument to
Measure user perceived service
quality of mHealth
Paper 4 : An autonomous mobile
system for the management
of COPD

Paper 5: Mobile health in emerging countries: A survey of research initiatives in Brazil

Paper 6: The feasibility of using SMS as a health survey tool: An exploratory study in patients with rheumatoid arthritis

Paper 7: H_pe for mHealth: More " $y$ " or "o" on the horizon?

Paper 8: Context-based and rulebased adaptation of mobile user interfaces in mHealth

Paper 9: A Proposal of mobile system to support scenario-based learning for health promotion

Paper 10: Status and trends of mobile-health applications for iOS devices: A developer's perspective

Paper 11: mCHOIS: An Application of mobile technology for childhood obesity surveillance

\author{
Author/year \\ Brown et al. [43]

\section{Main results and conclusions} \\ This work analyzes the assessment model ITUEM \\ (Health-ITUEM) usability in adolescents when \\ evaluating the usability of Health Apps
}

Balsam et al. [44]

Akter et al. [31]

This work aims to improve the operation of the optical detector in mobile phones through the expansion of fluorescent signals to be used in health apps with diagnostic purposes

Pilot study to develop a scale for measuring the quality perceived by the user regarding the mHealth which showed a clear link between service quality and satisfaction, as well as satisfaction and continuity in use, as well as between the quality of service and continued use

Van der Heijden et al. [25]

Iwaya et al. [25]

Work based on the development of an app to detect exacerbations in COPD patients through the use of a spirometer and pulse oximeter. The evaluation showed that the model can reliably detect exacerbations and the pilot study suggests that an intervention based on this system may be successful

Systematic review to see the state of development of mHealth initiatives in Brazil. Most projects were focused on health surveys and surveillance and patient records and monitoring, the majority being deployed as prototypes for testing and being supported by the university

Lee et al. [26]

This research tests the feasibility of using SMS as a tool for the study of patients with rheumatoid arthritis. It proved feasible, reducing response time and at a lower price than mail or postal mail

Labrique et al. [27]

Letter to the editor in which appear a criticism of the changes and development that is occurring in mHealth, with a saturation of pilot studies, unclassifiable designs impossible to extrapolate to larger sample sizes and with a lack of evidence

Alnanih et al. [28]

Study where a user interface (MUI) is developed to serve as a bridge between any application and the health professional. The results showed that the proposed improvement did not increase the efficacy, safety, navigation, productivity or efficiency in the work. Neither it increased its satisfaction

Menezes et al. [29] The document presents "KNOW Communities" which includes a series of virtual scenarios where the goal is to present health problems for students, workers and population, allowing developing educational activities. No results are displayed

Liu et al. [13]

Study of 159 applications from the AppStore, approached from the perspective of developers, looking at features like architecture, interface design, etc. The purpose of the text is to be used as a reference and guide for anyone who wants to develop on iOS

Datta et al. [45]

The development of an application is described to facilitate the collection of data (mChois) that aims to overcome the limitations of a web for childhood obesity (chois) that depended on the Internet. The application allows the collection and storage of data locally and is now being used by "The Illinois Department of Human Services (IDHS)" for school health program 
Table 2 continued

Paper
Paper 12: Evaluating the use of
mobile phone technology to
enhance cardiovascular disease
screening by community health
workers
Paper 13: Recognizing whether
sensors are on the same body
Paper 14: LabPush: a pilot study
of providing remote Clinics with
laboratory results via short mes-
sage service (SMS) in Swaziland,
Africa-a qualitative study

Paper 15: Thousand-fold fluorescent signal Amplification for mHealth diagnostics

Paper 16: A literature review on attitudes of health professionals towards health information systems: from e-Health to $\mathrm{m}$ - Health

Paper 17: Are we sure that Mobile Health is really mobile? An examination of mobile device use during two remotely- delivered weight loss interventions

Paper 18: A Classification scheme for analyzing mobile apps used to prevent and manage disease in late life

Paper 19: A data encryption solution for mobile health apps in cooperation environments

Paper 20: Adherence to evidencebased guidelines among diabetes self-management apps

Author/year
Surka et al. [46]
Cornelius and Kotz
[47]

Hao et al. [35]

Balsam et al. [32]

\section{Sezgin and Ozkan Yildirim [30]}

Wang et al. [15]

Silva et al. [87]

Breland et al. [86]
Main results and conclusions

The purpose of this study is to develop an application that assess the risk of cardiovascular disease, assessing its impact on health staff and the duration of the screening, compared with paperbased. The application was considered easy to use, faster and more accurate, but with a worse visual display to explain the risk to the population

The proposition of this paper is to improve connectivity with sensors Smartphone. It shows a probabilistic model to look for correlations between sensors and accelerometers of your device to avoid the above mentioned problem. The new model achieved an accuracy of $85 \%$

The study presents the use of short message service (SMS) "LabPush" to send the most important results to the professionals, to facilitate and accelerate decision-making. SMS method shortened the turnaround time of results. The professionals expressed satisfaction at the prospect of starting treatment earlier, because communication with the laboratory was improved and if results were lost, it was easily recovered by a call

Capillary array focus and image stacking computer that is capable of amplifying the weak fluorescent signals, thereby improving the sensitivity of the optical sensors of mobile devices. It is the same studio as Article 2

The study presents a review of the acceptance of health information systems by health professionals. Through various theoretical models it gets explained the purpose of the health professionals in the use of health technologies with high rates of variability

Turner-McGrievya and This study compared the effectiveness in terms of access to information in the traditional way (desktops, laptops...) against mobile, and if they affect the results of commitment and health in a weight loss intervention in 137 patients. It showed greater weight loss for those who used the mobile device

The study carried out the classification of 119 mobile applications from the AppStore in the categories of health and welfare for the elderly. The classification was carried out satisfactorily, reaching $100 \%$ agreement between what was developed in the study and what was conducted by two external encoders. This system give you a view of the distribution of applications to developers and allow users to know which one suits your needs.

The study has the goal to develop a system of data encryption (DE4MHA) to guarantee the security of data. That the app had a similar behaviour to the one it would have without the data encryption system was achieved, so that quality was also guaranteed. The system could be adapted to other apps of mHealth

The research has the goal to evaluate if 411 apps used for diabetes self-management followed the guidelines based on scientific evidence. From the 7 self- management behaviours recommended by the American Association of Diabetes Educators (AADE) most of them just accomplished 1 or 2 
Table 2 continued

\begin{tabular}{|c|c|c|}
\hline Paper & Author/year & Main results and conclusions \\
\hline $\begin{array}{l}\text { Paper 21: A mobile app offering } \\
\text { distractions and tips to cope with } \\
\text { cigarette craving: a qualitative } \\
\text { study }\end{array}$ & Ploderer et al. [16] & $\begin{array}{l}\text { The article shows the development of the app "Dis- } \\
\text { tractMe" which permits whoever wants to stop } \\
\text { smoking, the access to different type of distrac- } \\
\text { tions and tips to cope with smoking craving. With } \\
\text { a small simple of } 14 \text { smokers, } 5 \text { patients reported } \\
\text { a favourable use of the evasive technique and } \\
\text { other } 9 \text { reported a favourable use permiting to } \\
\text { avoid smoking instead of other activities }\end{array}$ \\
\hline $\begin{array}{l}\text { Paper 22: A newborn baby care } \\
\text { support app and system for } \\
\text { mHealth }\end{array}$ & Kuo et al. [36] & $\begin{array}{l}\text { The study describes the development of an app } \\
\text { with two subsystems "Baby's Health Record Sys- } \\
\text { tem (BHRS) and "Baby Care Consultation System" } \\
\text { (BCCS) which allows mums to have a better care } \\
\text { of their newborn. From the } 64 \text { women studied, } \\
\text { the most of them were satisfied with the app }\end{array}$ \\
\hline $\begin{array}{l}\text { Paper 23: A Personal health } \\
\text { information toolkit for health } \\
\text { intervention research }\end{array}$ & Kizakevich et al. [49] & $\begin{array}{l}\text { The article presents the development of the toolkit } \\
\text { PHIT(Personal Health Intervention Toolkit) to } \\
\text { facilitate the investigation and development of } \\
\text { applications in health interventions in chronic } \\
\text { diseases, health control with data collection, etc. } \\
\text { Most of the } 31 \text { patients who participated, valued } \\
\text { the app over percentile } 95 \text {. }\end{array}$ \\
\hline $\begin{array}{l}\text { Paper 24: A smartphone-based } \\
\text { pain management app for ado- } \\
\text { lescents with cancer: establish- } \\
\text { ing system requirements and a } \\
\text { pain care algorithm based on } \\
\text { literature review, interviews, and } \\
\text { consensus. }\end{array}$ & Jibb et al. [40] & $\begin{array}{l}\text { The development of an algorithm of decision was } \\
\text { aimed in base on the evidence for the better pain } \\
\text { care in adolescents with cancer. } \\
\text { It was determined that the interventions including } \\
\text { the support of therapists are more efficient and } \\
\text { it was recommended to include patients and/ } \\
\text { or relatives both in the development and in the } \\
\text { design of the app }\end{array}$ \\
\hline $\begin{array}{l}\text { Paper } 25 \text { : Availability and quality } \\
\text { of mobile health app privacy } \\
\text { policies }\end{array}$ & Sunyaev et al. [50] & $\begin{array}{l}\text { The document presents an analysis in the privacy } \\
\text { policy of the apps of mHealth.The analysis is } \\
\text { focused on the } 600 \text { mobile Health app more used } \\
\text { for Android and IOS. It showed that only the } 30 \% \\
\text { had privacy policy and these were insufficient }\end{array}$ \\
\hline $\begin{array}{l}\text { Paper 26: Behavior change } \\
\text { techniques implemented in elec- } \\
\text { tronic lifestyle activity monitors: a } \\
\text { systematic content analysis }\end{array}$ & Lyons et al. [24] & $\begin{array}{l}\text { The study analyses } 13 \text { electronic lifestyle activity } \\
\text { monitors to find out which of the fourteen tech- } \\
\text { niques identified in the literature are founded } \\
\text { with the aim of increasing them. All them had } \\
\text { a similar behaviour, suing the app to direct the } \\
\text { information. The techniques and recommenda- } \\
\text { tions were based on the scientific literature. From } \\
\text { the } 14 \text { identified as potentially efficient in behav- } \\
\text { iour change, the monitors included between } 5 \\
\text { and } 10\end{array}$ \\
\hline $\begin{array}{l}\text { Paper 27: ClereMed: lessons } \\
\text { learned from a pilot study of a } \\
\text { mobile screening tool to identify } \\
\text { and support adults who have dif- } \\
\text { ficulty with medication labels }\end{array}$ & Grindrod et al. [17] & $\begin{array}{l}\text { The study presents a prototype of an app } \\
\text { ("ClereMed") to identify people who have diffi- } \\
\text { culty reading, poor ability in handling medication } \\
\text { and cognitive impairment, and to assess the } \\
\text { acceptance of touch devices in older people. We } \\
\text { Studied } 47 \text { elderly. } 84 \% \text { of participants stated } \\
\text { that the application was easy to use. In terms } \\
\text { of reading difficulty, it was correctly identified } \\
72 \% . \text { Only } 21 \% \text { of participants showed cognitive } \\
\text { difficulties }\end{array}$ \\
\hline $\begin{array}{l}\text { Paper 28: Commercially available } \\
\text { mobile Pone headache diary } \\
\text { apps: a systematic review }\end{array}$ & $\begin{array}{l}\text { Hundert A.S., et al. } \\
\text { [14] }\end{array}$ & $\begin{array}{l}\text { In this paper } 7 \text { rules guideline was created as } \\
\text { minimum requirements for considering that an } \\
\text { application was useful in the management and } \\
\text { control of headache. } 38 \text { apps were studied. None } \\
\text { of them met all the criteria and neither was pub- } \\
\text { lished in scientific literature, and only } 3 \text { met five } \\
\text { of them. It showed a lack of scientific knowledge } \\
\text { and evidence in this type of application }\end{array}$ \\
\hline
\end{tabular}


Table 2 continued

Paper
Paper 29: Comparison of mobile
apps for the leading causes of
death among different income
zones: a review of the literature
and app stores

Paper 30: Comparison of traditional versus mobile app self- monitoring of physical activity and dietary intake among overweight adults participating in an mHealth weight loss program

Paper 31: Contemporary vascular smartphone medical applications
Paper 32: Design of an mHealth app for the self-management of adolescent type 1 diabetes: a pilot study

Paper 33: Development of a Smartphone App for a Genetics Website: The Amyotrophic Lateral Sclerosis Online Genetics Database (ALSoD)

Paper 34: Development of DASH Mobile a mHealth lifestyle change intervention for the management of hypertension

Paper 35: Effectiveness of a smart phone app on improving immunization of children in rural Sichuan Province, China: study protocol for a paired cluster randomized controlled trial

Paper 36: Electronic data capture in King et al. [38] a rural African setting: evaluating experiences with different systems in Malawi

Paper 37: Evaluation of an mHealth intervention aiming to improve health-related behavior and sleep and reduce fatigue among airline pilots

van Drongele et al. [33]

\section{Author/year}

Martínez-Pérez et al.

Carter et al. [52]

urner-McGrievy et al. [37]

Cafazzo et al. [42]

Abel et al. [53]

Mann et al. [23]

Chen et al. [54]

\section{Main results and conclusions}

It is a review that seeks to compare research and the number of mobile applications for diseases and conditions that are major causes of death according to the $\mathrm{WHO}$, based on the income of regions. The results show applications of high-income regions are more common, with some exceptions such as HIV/AIDS and cancer of airway. It shows more effort in commercial work than in the research in this application field

The paper presents a study of 96 overweight individuals, whose purpose is to analyse the relationship between diet, self-monitoring of physical activity and eating habits by following different types of monitoring (mobile applications, web diary on paper). The group using the mobile application to control physical activity showed better results

The text presents a search for the availability of applications with vascular diseases as a theme in main application stores, as well as possible integration in practice. 49 were located, of which only 13 documented the participation of a medical professional in the design or content. It was concluded that the use of mHealth could be potentially beneficial, but it also showed a lack of high scientific quality apps

The objective is the design, development and implementation of a study for the management of type 1 diabetes in 20 adolescents. There was an increase in daily average frequency of measurement by $50 \%$. Another study is needed to assess the improvement of $\mathrm{HbA} 1 \mathrm{c}$

The paper presents the development of a mobile version of the web "Genetics The ALS Online Database (ALSOD)" and an application for smartphone which allows easier and wider access. It showed an increase of $26 \%$ of visits to the website and a $230 \%$ increase in visits through mobile devices

It presents the development of "Mobile DASH" application for Android, based on the DASH diet for the control and management of hypertension is exposed. No results included

It presents the protocol of a study evaluating the effectiveness of an application to increase the level of immunization in the province of Sichuan (China)

The primary outcome is the total dose coverage and the secondary is the coverage in other five vaccines of the expanded program of immunization. No results are shown

The text seeks to highlight the advantages and disadvantages of different systems of electronic data capture (EDC) used simultaneously in rural Malawi, to increase information and research. Workers preferred the EDC to paper-based systems and create a profitable system in the long term

The study shows the effects of an intervention of $\mathrm{mHealth}$ in 502 airline pilots to reduce problems of fatigue, sleep and improve their perception of health through the app "MORE energy". The intervention group improved quality of sleep, fatigue, strenuous physical activity, diet and rest 
Table 2 continued

Paper
Paper 38: Evaluation of the
accuracy of smartphone medical
calculation apps
Paper 39: Exploring the usability
of a mobile app for adolescent
obesity management

of a mobile app for adolescent obesity management

Paper 40: Food and Drug Administration regulation of diabetesrelated $\mathrm{mHealth}$ technologies

Paper 41: FoodSwitch: A Mobile Phone App to Enable Consumers to Make Healthier Food Choices and Crowdsourcing of National Food Composition Data

Paper 42: Health professionals as mobile content creators: teaching medical students to develop mHealth applications

Paper 43: Ideas and enhancements related to mobile applications to support type 1 diabetes

Author/year
Bierbrier et al. [55]

Main results and conclusions

The objective of this document is to analyze the accuracy of smartphone medical calculation apps offered by different stores

14 apps were analyzed and 13 functions for each of them. 10 cases for each one were carried out, being the results compared to the manual calculations. The total accuracy was $98,6 \%$ and $43 \%$ of the apps had an accuracy of $100 \%$

O'Malley et al. [18]

The study proved the usability of the application "Reactivate" for the control of obesity in 10 adolescents. There were not showed results about the clinical effectiveness, although it was evaluated that it was more efficient

It was also collected the need of the app working for iPhone, that the colours were brighter and the text bigger

Brooke and Thompson [56]

Dunford et al. [19]

The text tries to shed light on the regulation of FDA about the applications related qwith diabetes and it contributes with a convincing conclusion by which more clarity is required in the regulation of the applications devoted to diabetes

The paper describes the development of a mobile application ("FootSwitch") to help Australian population to a better understanding of the nutritional information of the foods in order to facilitate a better choice, using a database of 17,000 packaged foods that could be increased through "crowd-sourcing"

Masters [57]

The research highlights the need to train medical students in the development of applications. "IBuildApp" is presented as applications development environment.107 students were surveyed about the perception of the project. The most perceived need was to increase learning, specially the programming which was considered the main factor of influence. The impact of the experience was similar to other studies

Pulman et al. [20]

The objective of this study was to develop an application for the management of type 1 diabetes in young people. The app was aimed to offer quality services and improve the own "healthrelated quality of life (HRQOL)" of users, with input from experts and end-user over design. The researchers conducted the development of three prototypes of which one was chosen by nine respondents. Thus the data for prototyping and improving existing ones were taken, trying to suit the needs of the age group

Paper 44: iMHere: A novel mHealth Parmanto et al. [58]

The paper presents the development of one mobile application titled "IMHere" and a medical portal to provide two-way communication. The application has the function of supporting self-care tasks, receiving and sending data of adherence and self-care regimes under supervision. The clinical phase of the study was being conducted. No results are shown

Paper 45: Implementation of an Vriend et al. [59]

The paper presents an evaluation of the effectiveness of the App "Versterk je Enkel" focused on the prevention of recurrent ankle sprains. The application reached only $2.6 \%(n=82)$ of the target population. The use of the resource pointed that compliance with the integrated program was low. Efforts to ensure the proper collection and the use of app by the target population are needed 
Table 2 continued

\begin{tabular}{|c|c|c|}
\hline Paper & Author/year & Main results and conclusions \\
\hline $\begin{array}{l}\text { Paper 46: Improving adher- } \\
\text { ence physical activity with a } \\
\text { smartphone application based } \\
\text { on adults with intellectual dis- } \\
\text { abilities (APPCOID) }\end{array}$ & $\begin{array}{l}\text { Pérez-Cruzado and } \\
\text { Cuesta-Vargas [60] }\end{array}$ & $\begin{array}{l}\text { Given the low levels of physical activity in people } \\
\text { with mental disabilities, a research protocol } \\
\text { aimed to improving the adherence to physical } \\
\text { activity (based on the use of an app) in these } \\
\text { patients is presented. No results are displayed }\end{array}$ \\
\hline $\begin{array}{l}\text { Paper 47: Low- intensity self- } \\
\text { management intervention for } \\
\text { persons with type } 2 \text { diabetes } \\
\text { using a mobile phone-based } \\
\text { diabetes diary, with and without } \\
\text { health counseling and motiva- } \\
\text { tional interviewing: protocol for a } \\
\text { randomized controlled trial }\end{array}$ & Ribu et al. [41] & $\begin{array}{l}\text { The document presents a research aimed to assess } \\
\text { the effectiveness in controlling diabetes of } 151 \\
\text { patients, using three different interventions, one } \\
\text { of them based on the use of one app. } 17.2 \% \\
\text { of the participants were lost to follow up at the } \\
\text { publication time and } 7.3 \% \text { were still in the trial. } \\
\text { It indicated that the results would be published } \\
\text { in } 2014\end{array}$ \\
\hline $\begin{array}{l}\text { Paper 48: Mapping mHealth } \\
\text { Research: A Decade of Evolution }\end{array}$ & Fiordelli et al. [61] & $\begin{array}{l}\text { The paper provides an overview of how the emer- } \\
\text { gence of the new generation of phones has led } \\
\text { to research on eHealth between } 2002 \text { and } 2012 \text {, } \\
\text { studying a sample of } 117 \text { papers. Most of them } \\
\text { were published in medical journals, highlighting } \\
\text { studies aimed to assess the control of chronic } \\
\text { diseases through the use of mobile devices. It is } \\
\text { concluded that mapping the evolution of this } \\
\text { topic will allow a better understanding of their } \\
\text { strengths and weaknesses, providing a very use- } \\
\text { ful information for future developments }\end{array}$ \\
\hline $\begin{array}{l}\text { Paper 49: mHealth 2.0: experiences, } \\
\text { possibilities, and perspectives }\end{array}$ & Becker et al. [21] & $\begin{array}{l}\text { The paper is an opinion letter referring to the } \\
\text { importance of mHealth as a tool to provide } \\
\text { universal access to services, the importance of } \\
\text { taking into account developmental psychosocial } \\
\text { variables and the model of technological devel- } \\
\text { opment of countries. It also says that criticism } \\
\text { and reviews help users to trust these applications } \\
\text { and test them, so inter-professional collaboration } \\
\text { becomes essential in mHealth } 2.0\end{array}$ \\
\hline $\begin{array}{l}\text { Paper 50: mHealth and mobile } \\
\text { medical Apps: a framework to } \\
\text { assess risk and promote safer use }\end{array}$ & Lewis and Wyatt [62] & $\begin{array}{l}\text { The document identifies various risks that mobile } \\
\text { applications can pose to patient safety. A generic } \\
\text { risk framework is also developed for users and } \\
\text { developers, being a useful tool for the evaluation } \\
\text { of specific applications in any particular context }\end{array}$ \\
\hline $\begin{array}{l}\text { Paper 51: mHealth: a strategic field } \\
\text { without a solid scientific soul. a } \\
\text { systematic review of pain-related } \\
\text { apps }\end{array}$ & $\begin{array}{l}\text { de la Vega and Miró } \\
\text { [63] }\end{array}$ & $\begin{array}{l}\text { A systematic review of the pain-related apps } \\
\text { available in scientific databases and the main } \\
\text { application shops was carried out to provide an } \\
\text { overview of the current state of development of } \\
\text { mHealth. } 47 \text { papers and } 283 \text { apps were found, } \\
\text { showing a big gap between the research part } \\
\text { and trade, since the vast majority of applications } \\
\text { was not supported by scientific evidence }\end{array}$ \\
\hline $\begin{array}{l}\text { Paper 52: mHealth data collector: } \\
\text { an application to collect and } \\
\text { report indicators for assessment } \\
\text { of cardiometabolic risk }\end{array}$ & Shishido et al. [64] & $\begin{array}{l}\text { The paper presents "mHealth Data Collector", an } \\
\text { application that contains data and information } \\
\text { associated with metabolic risk. After interview- } \\
\text { ing } 45 \text { health professionals who had used it, the } \\
\text { researchers evidenced a reduction of time in } \\
\text { the interview, a better collection, organization } \\
\text { and retrieval of data, as well as standardization } \\
\text { of the information entered into the system. The } \\
\text { assessment of usability (ease of use, charging time, } \\
\text { selecting the screen resolution, etc.) was also very } \\
\text { positive }\end{array}$ \\
\hline
\end{tabular}


Table 2 continued

Paper
Paper 53: mHealth tools for the
pediatric patient-centered medi-
cal home
Paper 54: Mobile applications for
diabetics: a systematic review
and expert-based usability
evaluation considering the
special requirements of diabetes
patients age 50 years or older

Paper 55: Mobile apps in cardiology: review

Paper 56: Mobile clinical decision support systems and applications: a literature and commercial review

Paper 57: Mobile health applications for the most prevalent conditions by the World Health Organization: review and analysis

Paper 58: Mobile health applications: the patchwork of legal and liability issues suggests strategies to improve oversight

Author/year
Slaper and Conkol
[65]

Arnhold et al. [83]

Martínez-Pérez et al. [66]

Martínez-Pérez et al. [67]

Martínez-Pérez et al.

Yang and Silverman [69]

\section{Main results and conclusions}

This paper is a review where performance and conceptual framework of some tools to perform the "pediatric patient-centered medical home $(\mathrm{PCMH})$ " are discussed. This PMTCT is defined as a place to care for this type of patient which have to be accessible, continuous, comprehensive, family-centered, coordinated, compassionate and culturally effective. The document presented mHealth as a resource that can help to satisfy this necessity

This document is a systematic review of 656 applications available to assist in the self-management of diabetes mellitus types 1 and 2, considering the range of functions, groups of target users, etc. $10 \%$ was used to evaluate the usability. An increase in the number of apps from 2008 to 2013 was appreciated and most ot them offered only one function and were intended for patients. $34.5 \%$ provided general information about the disease. Usability decreased with increasing number of functions and was moderate to good for users over 50 years

The study presents a review of the literature of the main databases (406 papers) and applications stores (710 apps) to study the resources available with respect to cardiovascular disease. Only few items related to mobile applications were found. A great disparity was evident in the field of cardiology applications, having a lot of research on certain issues, while others were abandoned. It also emphasized that there was no link between the offered apps and the scientific production

The document presents a review of applications developed to help in clinical decision making (CDDS) at the main databases (92 items) and the Android and Apple stores (192 apps). Articles made explicit that apps were developed for research purposes and were not available in stores. The Apps available were devoted to general practice and almost half directed to specialists. Developers focused on diseases that are the main cause of death, more prevalent and more disabling

Based on the eight most prevalent health conditions marked by WHO in 2004, the study presents a review of the literature (247 papers) in different databases and applications (3673 apps) of the main stores. Distribution of mobile applications did not correspond to the prevalence of health conditions. Results also found less applications in the literature, which led to think that there is more economic commercial motivation than research reasons. Diabetes and depression, health conditions prevalent in developed countries, were the focus of most research and applications

The text shows the state of the US legislation regarding $\mathrm{mHealth}$. The lack of regulation regarding medical leaves, responsibility, possible negligence by the professional using an application, privacy when storing patient data, etc., are complex issues to cover despite legislative efforts 
Table 2 continued

Paper
Paper 59: Mobile medical and
health apps: state of the art,
concerns, regulatory control and
certification
Paper 60 : Mobile mental wellness
training for stress management:
feasibility and design implica-
tions based on a one-month
field study

Paper 61: mSpray: a mobile phone technology to improve malaria control efforts and monitor human exposure to malaria control pesticides in Limpopo, South Africa

Paper 62: Physical activity, sedentary behavior and total wellness changes Among sedentary adults: a 4-week randomized

Paper 63: Pilot study using mobile health to coordinate the diabetic patient, diabetologist, and ophthalmologist controlled trial

Author/year

Ahtinen et al. [71]

Eskenazi et al. [34]

Barwais et al. [72]

Tsui et al. [73]

\section{Main results and conclusions}

The document presents a review of studies evaluating health applications. The concept of "application as a medical device" and regulation that currently exists in the US and Europe is also discussed. An example of voluntary application for certification in the US market named "Happtique Health App Certification Program" is presented in the text. As to make a thorough control of the apps is very complicated, it is proposed to educate patients and users about what is the best use to give to these applications

The paper is focused on the study of the use and results of the "Oiva" application, which was developed for the prevention and management of work-related stress and mental health problems in 15 workers. Significant changes were observed in the scores of stress and satisfaction with life, but not in the psychological flexibility. A significant increase was also evident in the improvement or maintenance of well-being, learning new skills and gain new ideas. It was perceived as easy to use, acceptable and useful

The paper examines the effectiveness and usability of the app "mSpray" in 13 workers. The app was created to collect data from areas under sprays to control malaria, seeking to improve the currently used, paper-based system. The application included geo-location and use of spreadsheets to lead a real-time observation. The times were improved and errors with the above method were detected. Workers preferred "mSpray" system over the traditional system.

The study presents a four-week intervention program with 33 individuals using a staff monitor online activity, designed to reduce sedentary time and increasing physical activity. Results were compared to control group which continued normal life. Sedentary time was reduced in the intervention group, and the time of light, moderate and intense activity was increased. Researchers do not appreciate changes in the control group

The paper presents a pilot study with 60 diabetic patients to assess the "Sightbook" application, which seeks the coordination between the patient, the physician who follows the diabetes patient and ophthalmologist and offers a self-assessment of visual function. The app is considered useful because research showed that a high percentage had diabetic retinopathy and other risk factors, so to consult ophthalmologist was necessary

Paper 64: Preferences for a Mobile HIV Prevention App for Men Who

Goldenberg et al. [74] The paper describes how it should be an application that would promote the homosexual population to participate in HIV prevention. To do this, several focus group discussions were conducted $(n=38)$. It was evidenced that apps should have innovative ideas, educate and engage men to motivate them to use the application. Feeling safe and have the confidence was important, so the importance of protecting the privacy language and stressed was highlighted. To achieve adherence to the App, it should be easy to use, attractive and pushing homosexuals to concern about their safety 
Table 2 continued

Paper
Paper 65: Randomized, controlled
pilot trial of a smartphone app
for smoking Cessation using
Acceptance and commitment
therapy

Paper 66: Sexual and reproductive health for young adults in Colombia: teleconsultation using mobile devices

Author/year

Lopez et al. [22]

Paper 67: Smartphone breast appli- Mobasheri et al. [75] cations-What's the evidence?

Paper 68: Study of the usability of spaced retrieval Exercise using mobile devices for Alzheimer's disease rehabilitation

Paper 69: Supporting cancer patients in illness management: usability evaluation of a mobile app

Paper 70: The current status of mHealth for diabetes: will it be Klonoff [78]

Mirkovic et al. [77]

\section{Main results and conclusions}

The paper shows a comparative study of two mobile applications to quit smoking ("SmartQuit" and "QuitGuide") based on different approaches. SmartQuit users open the application an average of 37 times versus 15 times from QuitGuide users. The quit rate was $13 \%$ vs. $5 \%$. The authors indicate that the experimental design and low sample size prevents extrapolate the effectiveness of Apps

This document describes the research with 58 young people and adults in Bogota, Colombia. The study is aimed to evaluate the use of an app focused on the resolution of questions on health with pre- and post-intervention survey. The main topics consulted were risks that they take not using a condom during sex, consumption of psychoactive drugs and lack of knowledge about sexually transmitted diseases. The results indicate that the strategy proposed was well accepted by young people. Although no significant result was evidenced, it is stated that the strategy proposed was well accepted by young people

The paper analyzed 185 applications focused on pathologies and breast problems. A large disconnect between the development of Apps and health professionals, and a marked lack of scientific evidence was showed. A review of the information provided is recommended, as well as add bibliographic references and mention the authors

The research consists in a clinical-trial with 10 participants in early stages of Alzheimer's, to whom was offering them two versions of the App "ADcope", to enhance their abilities to perform activities of daily living and to promote their independence and social participation. The results are better in version based on images; although there was a good adaptation to the use and satisfaction of participants in both of them

This study is focused on the analysis of design, functionality and usability of a prototype App "Mobile Connect", which is presented as a support to 7 cancer patients in managing their health, encouraging communication, management of symptoms, decision making, etc. Evidenced usability was very good (72\%). Researches also evidenced that to take into account the needs of users for developing this type of applications must be prerequisite for its development

This paper presents a review of the role of mHealth in diabetes, presenting it as a value resource to monitoring diabetic patients through applications with glycemic control, which can be added to monitor other values. Researchers discussed that apps facilitate the monitoring and planning of personal goals, enabling better patient outcomes. However, lack of research, quality and rigour, as well as the need to overcome barriers such as privacy, the clinical benefit and economic returns, make difficult to give them a clinical use 
Table 2 continued

Paper
Paper 71: The development of a
mobile monitoring and feedback
tool to stimulate physical activity
of people with a chronic disease
in primary care: a user-centered
design
Paper 72: The schisto track: a
system for gathering and moni-
toring epidemiological surveys
by connecting geographical
information systems in real time

Paper 73: Usage of multilingual mobile translation applications in clinical settings

Author/year
van der Weegen et al.
[79]

\section{Main results and conclusions}

Leal Neto et al. [80]

Albrecht et al. [81]

This paper describes the development of an application to monitor an increase physical activity in chronic patients. 15 patients and 16 health professionals were involved in the research. It emphasizes the need to develop apps under an user-centred model. No clinical results are shown

The document shows us the development and main features of the app "Schisto Track", created to facilitate the data collection on schistosomiasis. The app proved to be helpful to automate the activity, organizing data, retrieving, etc., so their use is recommended. In addition, the text describes how two types of access were used. A general access for users and other restricted to researchers involved in the project, ensuring that the database had information safe and confinable

Effectiveness "Xpromt" application as a tool to multilanguage support through interaction with the patient through a mobile device is evaluated in this research. Researchers offered the application to 39 health professionals. The results showed that, despite positively assess translation applications for communication with patients, there was no enthusiasm for "Xprompt". While experts had clear expectations, users will not see benefit over time to be used in clinical settings. Finally, the authors remark the importance of assessing the degree of user acceptance for the development of these apps

Paper 74: User Preferences and

Hilliard et al. [82] Design Recommendations for an mHealth App to Promote Cystic Fibrosis Self-Management
Paper 75: Weight loss-there is an app for that! But does it adhere to evidence-informed practices?
Breton et al. [84]

BinDhim et al. [85]
The study attempts to define the characteristics that an app for adolescents with cystic fibrosis must have, for which the researchers combined qualitative and quantitative techniques in 16 participants. They expressed that access to information, automate the prescription process, and encourage communication with the staff care and family using the app, are very important resources that could be present in the app. It was also assessed positively the creation of a social network to bring together people and families in order to share experiences

The paper reviews and summarizes the content of the applications available on iTunes in 2009 (204) according to 13 practical for weight control based on scientific evidence. No application included the 13 practices. They found much variability regarding the number of practices, including 2 of them (daily food and weight evaluation) in $30 \%$ of the apps. The most frequent resources were the interactive tool, nutritional data bases and educational material.

The paper presents a comparative study of the characteristics of 602 users of "Quit Advisor". This is an application to quit smoking. The research was carried out during 1 year in Australia, United Kingdom and United States. No significant differences in the average age of users and attempts to quit smoking between countries were found, but differences by gender and stage of change was evidenced. $77.5 \%$ of users who had used previously other apps health, expressed do not take into account the credibility of the developer 
Table 2 continued

Paper
Paper 77: Dietary Approaches
to Stop Hypertension: Lessons
Learned From a Case Study on
the Development of an mHealth
Behavior Change System

Paper 78: Daily mood ratings via text message as a proxy for clinic based depression assessment

Paper 79: Incorporating customer empowerment in mobile health

Paper 80: Anytime, anywhere access to secure, privacy-aware healthcare services: Issues, approaches and challenges

Paper 81: Clinical laboratory data: acquire, analyze, communicate liberate

Paper 82: Photograph-based diagnosis of burns in patients with dark-skin types: The importance of case and assessor characteristics

Paper 83: Mobile Health: empower- Bradway et al. [94] ing patients and driving change

Aguilera et al. [89]

Author/year

Mann et al. [88]

Anwar et al. [91] [92]

Boissin et al. [93]
Main results and conclusions

The study describes the development of an application of behavioural reducing hypertension based on the DASH diet. It takes into account the multimedia content, wireless devices (which can connect to the app), security and usability. The article concludes with 10 lessons learned during the development of the application, which highlights the need to break with tradition, the importance of a multidisciplinary approach, the platform features, the prototype must be flexible and scalable and the fact of that it is advisable to contact technological trade experts to grow through investors

The aim of this research was to determine whether the information derived from the ratings of mood through SMS could serve as a reliable indicator for assessing the mood in clinical settings. 33 patients with depression were studied. As a control the PHQ-9 (Patient Health Questionnaire-9) was used. The results show that the SMS could fulfill this role

Almunawara et al. [90] This paper presents a health model that incorporates client empowerment in the mHealth in three dimensions: personal, social and medical. In addition, a survey was conducted to 366 individuals to assess their perception of the subject, as well as requirements for the model. Researchers concluded that the model integrated the widest scope of empowerment in the three proposed areas, serving as a guide to extend the empowerment of customers through mHealth

This paper consists in a review aimed to rationalize and explore safety issues related to privacy in the mHealth. The authors examine existing approaches, addressing issues such as institutional infrastructure and government and policy challenges among countries to address the issues of security and privacy

Azzazy and Elbehery

This to acquire, analyze, communicate, and deliver clinical laboratory data. The paper concludes that this resource can dramatically improve the quality and quantity of health assistance offered in the areas of limited resources

This study evaluated whether photographs of burns taken with a mobile from patients with darker skin types, could be used for diagnosis. 21 cases of varying complexity were studied and conducted a survey through the web. It was concluded that the size and depth of burns in these patients could be evaluated with photographs, at least as well as with the simple view in clinical settings, since the average accuracy rates were 67.5 and $66.0 \%$ respectively

This document, after analyzing (literature review) the development of mHealth in the field of diabetes, concludes that although there has been good progress in apps for this medical condition, only a few of them have been validated and recognized to be used as tools for self-management of the disease. Therefore stresses the need to propose measures including the creation of a protocol to choose and use these tools or to establish financing plans and sustainability 
Table 2 continued

Paper
Paper 84: Electronic personal
maternity records: Both weband
smartphone services
Paper 85: From black box to
toolbox: Outlining device func-
tionality, engagement activities,
and the pervasive information
architecture of mHealth interven-
tions
Paper 86: BP here, there, and
everywhere - mobile health
applications (apps) and hyper-
tension care
Piabetes Self-Care System on
patients' knowledge, behavior
and efficacy

Paper 88: Apps for life change: Critical review and solution directions

Paper 89: Opportunities and barriers in service delivery through mobile phones (mHealth) for Severe Mental Illnesses in Rajasthan, India: A multi-site study

Paper 90: Legal, Regulatory, and Risk Management Issues in the Use of Technology to Deliver Mental Health Care

\section{Author/year}

Chang et al. [95]

Danaher et al. [96]

Green [97]

Guo et al. [98]

Helf and Hlavacs [99]

Jain et al. [100]

Kramer et al. [101]
Main results and conclusions

This paper presents a multi-platform information system (web and smartphones) to help women during pregnancy. 5 developers evaluated the usability through heuristics model of Nielsen, and 68 pregnant women completed a satisfaction survey. $80.9 \%$ of respondents stated that the system was useful for controlling pregnancy

This review examines two important aspects in the design of mHealth interventions: mobile device functionality and the data architecture, which determines its ability to bring information to mobile phones, PCs and other devices. They conclude that mHealth interventions developers should work on these aspects to engage participants and promote the desired change in behaviour to achieve health

Editorial referred to the promising potential of Apps health surveillance, monitoring and management of blood pressure in hypertensive patients is done

In this research, a system called "Mobile Diabetes Self-Care System", for diabetes type 2 was evaluated. The system was created to facilitate patients to improve their capacity for self-care and trying to be flexible in time, place and developed options use. The effectiveness of the system was assessed in 28 individuals who completed questionnaires before and after the intervention. The results indicated that the mobile system had improved the knowledge and behaviour of patient self-management by $17 \%$ and $22 \%$, respectively

This review is focused on the current lack of scientific use in application development, inefficient and selective incorporation of gamification, low levels of customization and potential privacy and trust. Due to the multidisciplinary nature of this set of problems, the text proposes frameworks integrated and user-centered as the best solution.

The document shows information about availability, usage patterns, barriers to mobile technology and felt needs for mental health services for patients with mental illness in the region of Rajasthan (India). 72 patients were interviewed. The preferred mode for delivery of service was through calls, telephone help lines for crisis resolution and follow-up of stable patients. The text concludes that the use of mobile technology has great potential for these patients.

This review focuses on risk management related to mobile health applications and the use of social networks to provide services "Telemental Health" (TMH), resolving some concerns about the risks and developing a framework to effectively manage the risks associated with caring through $\mathrm{TMH}$. The authors conclude that while it is important to be aware of these issues, the general principles to provide good clinical care, are the use of standards of practice set for the field of mental health, remain the core of the safe and effective practice 
Table 2 continued

\begin{tabular}{|c|c|c|}
\hline Paper & Author/year & Main results and conclusions \\
\hline $\begin{array}{l}\text { Paper 91: A content analysis of } \\
\text { smartphone-based applications } \\
\text { for hypertension management }\end{array}$ & Kumar et al. [102] & $\begin{array}{l}\text { The study examines the quality and characteristics } \\
\text { of apps focused on the control of hypertension } \\
\text { (HTA). The vast majority offered tracking figures } \\
\text { of blood pressure, weight or body mass index. } \\
\text { It is concluded that consumers have a strong } \\
\text { tendency to download and evaluate favourably } \\
\text { applications without validation, so the need for } \\
\text { greater supervision is evident in the develop- } \\
\text { ment of medical applications for hypertension, } \\
\text { especially when displayed in stores classified as } \\
\text { medical devices }\end{array}$ \\
\hline $\begin{array}{l}\text { Paper 92: The lifestylisation of } \\
\text { healthcare? 'Consumer genomics' } \\
\text { and mobile health as technolo- } \\
\text { gies for healthy lifestyle }\end{array}$ & $\begin{array}{l}\text { Lucivero and Prain- } \\
\text { sack [103] }\end{array}$ & $\begin{array}{l}\text { This review highlights the challenge posed by } \\
\text { "technologies for healthy living," because it is an } \\
\text { ambiguous space between the medical field } \\
\text { highly regulated and the consumer market, less } \\
\text { regulated. It is defined as the situation leads to } \\
\text { new ways to create (and make sense) knowledge } \\
\text { related to health. It also recognizes the enormous } \\
\text { potential of these technological advances }\end{array}$ \\
\hline
\end{tabular}

Paper 93: NOPA, Usability testing of Rodrigues et al. [104] an application to help patients during th treatment of infectious, and chronic diseases in Brazil

Paper 94: Feasibility of a lifestyle intervention for overweight/ obese endometrial and breast cancer survivors using an interactive mobile application

Paper 95: Ergonomic evaluation and design of a mobile application for maternal and infant health for smartphone users among lower-income class Filipinos

Paper 96: Exploiting the potential and facing the challenges of mobile devices: application examples

Paper 97: BPH laboratories: A proof-of-concept case on integrating smartphone diagnostics into clinical systems
McCarroll et al. [105] The study aimed to evaluate an intervention in 50 women survivors of endometrial or breast cancer with overweight or obese based on web (for contact with health professionals) and the "Loselt" application. Results indicated that intervention by modification of lifestyle offered through the web and with the support of the App is a viable short term option to reduce the weight

Nocum et al. [106] The paper presents a preliminary investigation to assess, using ISO 9126, a mobile application focused on disseminating relevant information to low-income pregnant women in the Philippines. Using the data collected, the researchers developed a new application ("Uyayi") that provides all the information requested and takes into account the functionality, reliability and ease of use application designed for this group

Nunes and SimoesMarques [107]

The document contents a review about apps related to health, from those used during leisure time until those for productivity time, trying to demonstrate their innovative potential, the analysis of the opportunities and remarking the challenges they represent

Olla et al. [108]

The document presents through a proof of concept an App ("Immediate -IDA- Diagnostics and Analytics"), how it can be used to acquire, analyze and transmit laboratory data from a pre-surgical hospital module to any system information. The result shown that the use of the App could be convenient to read results of a pregnancy test in a pre-surgical room in real time and transmit it to electronic health records. Finally, the text concludes that it is a useful tool for decision making in real time, improving patient safety and effectiveness attention 
Table 2 continued

\begin{tabular}{l} 
Paper \\
\hline Paper 98: Phone-based Interven- \\
tion under Nurse Guidance after \\
Stroke: Concept for Lowering \\
Blood Pressure after Stroke in \\
Sub-Saharan Africa
\end{tabular}

Paper 99: Enhanced healthcare personnel rostering solution using mobiletechnologies

Paper 100: Validation of a phone app for epilepsy diagnosis in India and Nepal

Author/year

Main results and conclusions

This paper proposes a procedure called "Phonebased Intervention under Nurse Guidance after Stroke (PINGS)" for self-management of blood pressure in patients who have suffered a stroke and are poorly controlled in sub-Saharan Africa. PINGS could include the implementation of a program led by nurses to the use and control technology (custom text messages and tele-monitoring at home) aimed at increasing motivation and self-care and increase adherence to antihypertensive therapy

Paschou et al. [110] This document refers to the validation in India and Nepal, with a greater sample (122 cases), from an app previously designed and tested in a pilot test The App intended to be an instrument to differentiate epileptic attacks from those not being by medical staff. Different degrees of clinical evidence were evidenced as well as high sensitivity values and specificity; for this reason its use and check ups is recommended in other places

Patterson et al. [111] This document refers to the validation in India and Nepal, with a greater sample (122 cases), from an app previously designed and tested in a pilot test

The App intended to be an instrument to differentiate epileptic attacks from those not being by medical staff. Different degrees of clinical evidence were evidenced as well as high sensitivity values and specificity; for this reason its use and check ups is recommended in other places

Paper 101: Review and analysis of existing mobile phone applications for health care associated

Schnall and Iribarren [112] infection prevention

Paper 102: Mobile-health: A review Silva et al. [113] of current state in 2015

Paper 103: The CAIDE Dementia

Sindi et al. [114] Risk Score App: The development of an evidence-based mobile application to predict the risk of dementia
The objective of this revision was to identify and provide a general vision of the apps available to support the prevention of hospital infections and to evaluate its functionality and potential uses in the clinical attention. 17 apps were studied. It was concluded that these could help to reduce the hospital infections, but due to the lack of available applications and functionality of the apps founded, it is required a greater development in its field

This article presents an exhaustive revision of the state of the technique in the field of $\mathrm{mHealth}$. The most important works published were studied, as well as the services of mHealth and the apps suggested by the industry. It was also approached the legislation and the necessity to define a paradigm of mHealth in the European Union and the United States. Finally, open and challenging issues were proposed about new solutions of mHealth for future works

The work presents the app "CAIDE Risk Score App" based in the toolkit (Cardiovascular Risk Factors, Aging, and Incidence of Dementia) to calculate tion were showed, taking into account that, in the moment of the development of the article, there were more than 700 downloads the risk to suffer dementia. No results of valida- 
Table 2 continued

\begin{tabular}{|c|c|c|}
\hline Paper & Author/year & Main results and conclusions \\
\hline $\begin{array}{l}\text { Paper 104: Online Filipino-Ameri- } \\
\text { cans' perspectives on informat- } \\
\text { ics-enabled health management }\end{array}$ & $\begin{array}{l}\text { Thompson and Valdez } \\
\text { [115] }\end{array}$ & $\begin{array}{l}\text { The purpose of this study was to understand the } \\
\text { perception of the perspectives of the Filipino- } \\
\text { Americans about three types of information } \\
\text { technology used for health management. An } \\
\text { online poll was administered to } 87 \text { participants } \\
\text { through Facebook. The sample was more likely } \\
\text { to use social networks (SNS), except the mobile } \\
\text { apps (mHealth) and hardly ever the personal } \\
\text { health records were used (PHR). The participants } \\
\text { informed about the advantages and disadvan- } \\
\text { tages of using this kind of technology for the } \\
\text { management of health (accessibility, credibility, } \\
\text { privacy, ease of use and utility, among them) }\end{array}$ \\
\hline $\begin{array}{l}\text { Paper 105: Sexual and reproductive } \\
\text { health and rights and mHealth } \\
\text { in policy and practice in South } \\
\text { Africa }\end{array}$ & $\begin{array}{l}\text { Waldman and Stevens } \\
\text { [116] }\end{array}$ & $\begin{array}{l}\text { This article explores from a qualitative methodol- } \\
\text { ogy (interviews to key informants and three case } \\
\text { studies), the intersections between mHealth, } \\
\text { health and the rights. } \\
\text { It is showed that the degree in which mHealth } \\
\text { tackles all the range of reproductive justice and } \\
\text { the health and sexual and reproductive rights is } \\
\text { limited, especially dealing with the government } \\
\text { initiatives. The document maintains that the } \\
\text { projects mHealth tend to avoid the controversial } \\
\text { aspects of sexual health, whereas it is developed } \\
\text { in favourable issues such as pregnancy and } \\
\text { maternity }\end{array}$ \\
\hline $\begin{array}{l}\text { Paper 106: Acceptability of mobile } \\
\text { health interventions to reduce } \\
\text { inactivity-related health risk in } \\
\text { central Pennsylvania adults }\end{array}$ & Yang et al. [117] & $\begin{array}{l}\text { The aim of this study was to typify the need and } \\
\text { the acceptability of mobile health interventions } \\
\text { of behaviour among the rural adults with sed- } \\
\text { entary lives in Pennsylvania and to evaluate the } \\
\text { interest and the value of the interventions based } \\
\text { in mobile apps. } 258 \text { participants with Smart- } \\
\text { phones filled a brief survey thorugh Internet in } \\
\text { October-November 2012. It was evidenced that } \\
\text { most of the surveyed would use a free app or a } \\
\text { low cost app to modify risk behaviours }\end{array}$ \\
\hline
\end{tabular}

quartile. The $49.1 \%$ of the papers appear in not indexed journals, specially in JMU. From our point of view, this fact highlights the high impact and newness that scientific work based on the use of mHealth technology represents for editors, allowing researchers to access to high impact publications and how new categories of are opening progressively.

However, the number of citations received of these articles is relatively small and widely dispersed. The sample shows an average of $6.35( \pm 13,56)$ references, excluding 2015 and 4.71 ( \pm 8.77$)$ counting this year. Two papers highlight with 74 [12] and 63 [13] citations, facing many that have never been referenced. Interestingly, these two articles were published in 2011 and 2012 (respectively), when the exponential growth in the number of publications on mHealth began. Thus, we can find just 2 papers in 2011 (1.9\% of total found) while we locate 45 in 2014 (42.5\%). Similarly, only four articles were found in 2012 (3.8 \%) and 26 in 2013 (24.8\%). Until October of 2015 we located 29 (27.4\%) papers published in 2015. In 2010 there were no relevant papers included in the search. This could be a sure sign that the scientific community is increasingly aware of the potential and the need to focus some research into this field.

Similarly, the mean number of citations received for years (excluding 2015), shows a clear downward trend ( $\mathrm{F}=36,72,3 \mathrm{df} ; \mathrm{p}<0.001)$. As the years pass, the average is down 
from the 62 items on average in 2011 till 1.53 in 2014. Temporal matters could explain this, i.e., it stands to reason that more recent articles have had less time to be referenced (and that is the main reason because we decided to exclude 2015 from this analysis), but it is a trend that is also seen in 2012 (with an average of 23 references) and 2013 (7.85). Post hoc tests found significant differences between every year $(\mathrm{p}<0.01)$.

In addition, considering the types of papers, we found that original researches are more prevalent (63.2\%), Besides this, we evaluated the type of the research carried out. We found descriptive studies (23.6\%), researches focused on technological development $(21.7 \%)$ and reviews (16 \%) highlighting over the rest (see Fig. 3). This fact happens because most of the articles are focused on the user data collection and evaluation from apps designed to assess adherence or modification of habits to healthier lifestyles (studies with larger sample sizes). Another percentage of the original researches is represented by small pilot studies or clinical trials with smaller sample sizes (5.7\%). As we mentioned above, reviews are also frequent, something justifiable given the exponential growth of publications. This situation force researchers to conduct periodically synthesis and evaluation of trends in the development of apps and main findings, as well as the errors most frequently committed (especially as the methodological design is concerned). Another significant point was to find nine papers from qualitative research which represent $9.4 \%$ of the types of research. It is understandable if we comprehend that this type of studies is very helpful in trying to expose the different realities of the new or unknown phenomena which we have a very little information or experience. A good example could be the expected results of interactions between mHealth apps and populations who want to improve their health. Furthermore, we were surprised because two of these articles had been published in computer science journals, where papers highly focused on applied and/or quantitative research are traditionally accepted. No statistically significant relation between the type of research and the number of citations received ( $p=0.297$ ) were found. Similarly, the type of research and the impact factor of the journal where the article is published did not show to be related $(\mathrm{p}=0.094)$.

We also wanted to know the link between the field of knowledge where the publishing journal is classified and the impact factor (see Fig. 4). We found a clear relation ( $\mathrm{p}<0.05)$, highlighting "Environment/Ecology", "Chemistry" and "Multidisciplinary" with higher average of impact factor. In any case, it is very important to evidence how

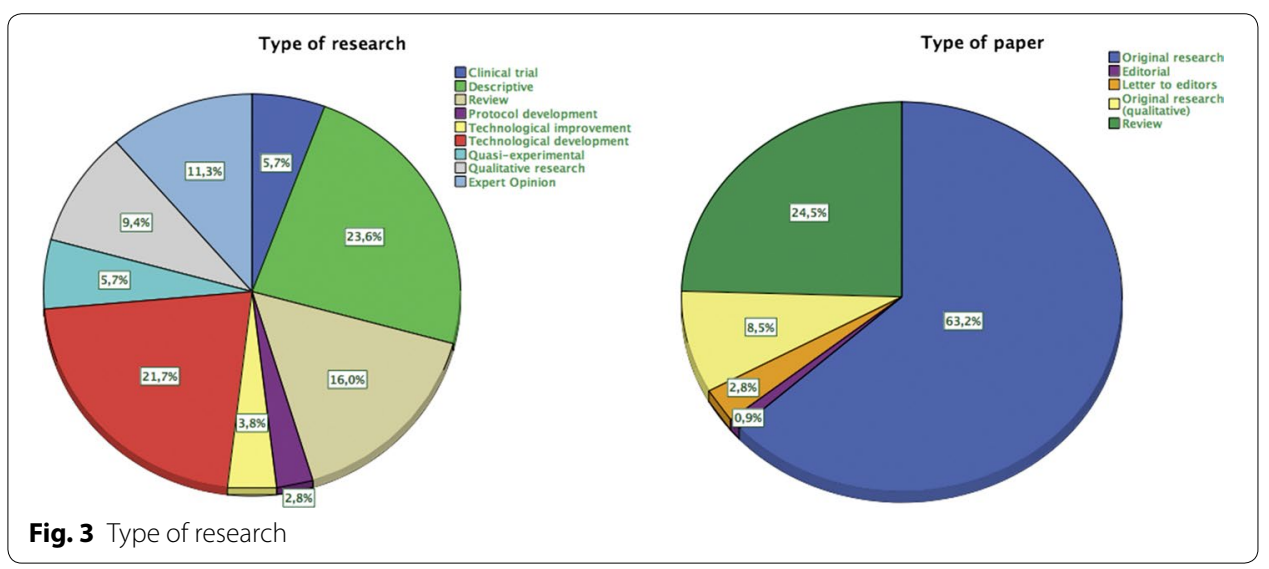




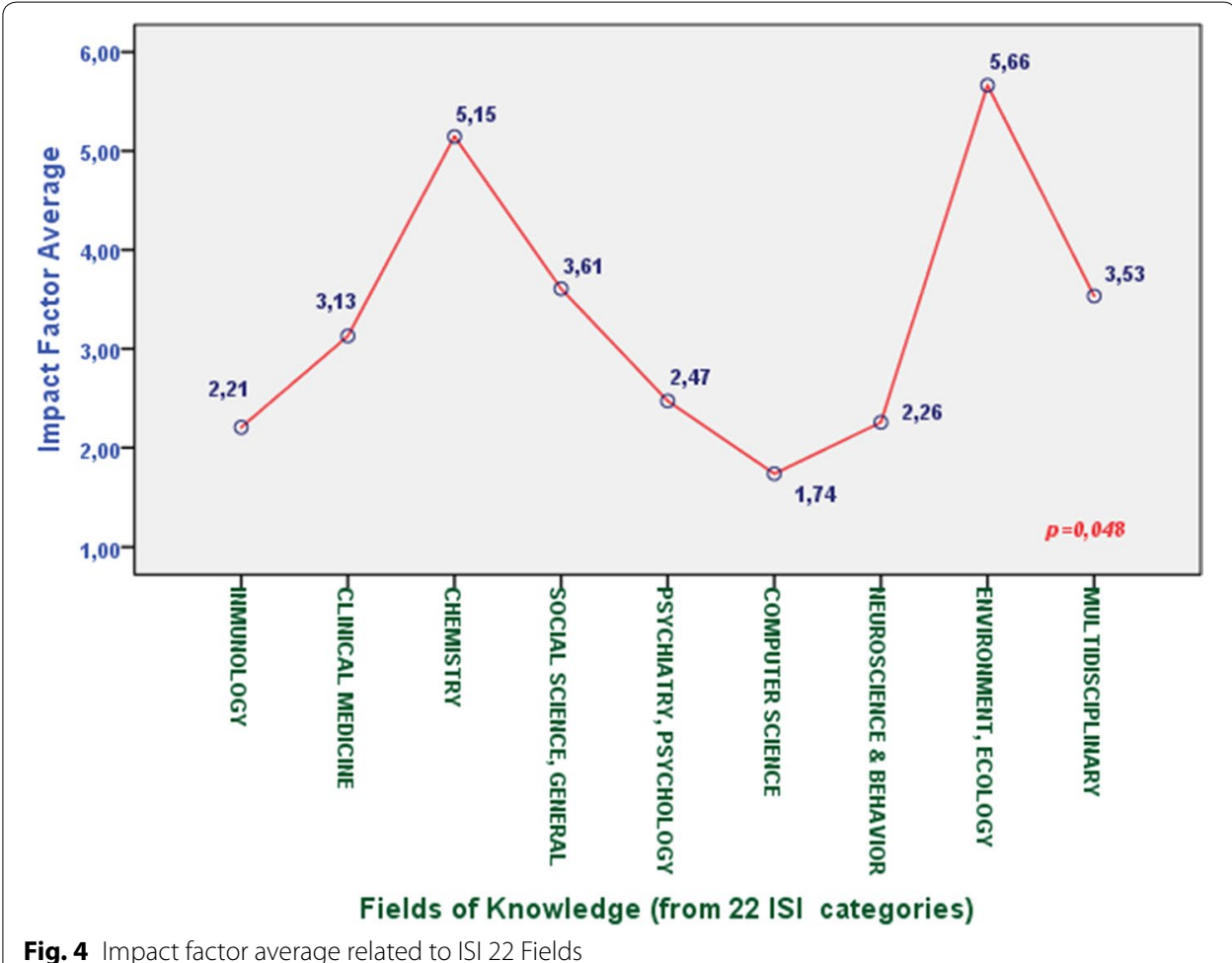

fields of knowledge, very far from health, a priori, accept papers focused on mHealth, which, from our point of view, demonstrate the deep impact that this new topic is generating in many fields of knowledge, related or not to health sciences.

\section{Research teams and the role of interdisciplinarity}

The results show that more than half of the reviewed papers (67.9\%) had the participation of at least two departments/institutions focused on different topics, reaching the maximum amount of five different topics (see Fig. 5). Only $32.1 \%$ [13-41] of the reviewed papers had participants focused on just one topic.

Besides this, we considered the interdisciplinarity, calculating the degree of diversity through Rao-Stirling (multidimensional index which includes the analysis of variety, balance and disparity). We found a very low and dispersed rates $(0.07 \pm 0.05)$. From our point of view, and related to the different topics where the departments involved in each paper are focused, these results mean that, although the diversity of the participants could seem high because they belong to different areas, finally they do not use the specific knowledge of each one, finding many references in each paper that belong to the same WoS categories (causing a low Rao-Stirling diversity).

\section{About interdisciplinary research teams, interdisciplinary publications, impact factor} and number of citations received

Although the visual examination of Fig. 6 shows a clear tendency for researches carried out by more than two departments/institutions from other fields of knowledge, are published in major journals, statistical analysis shows that these differences are not 


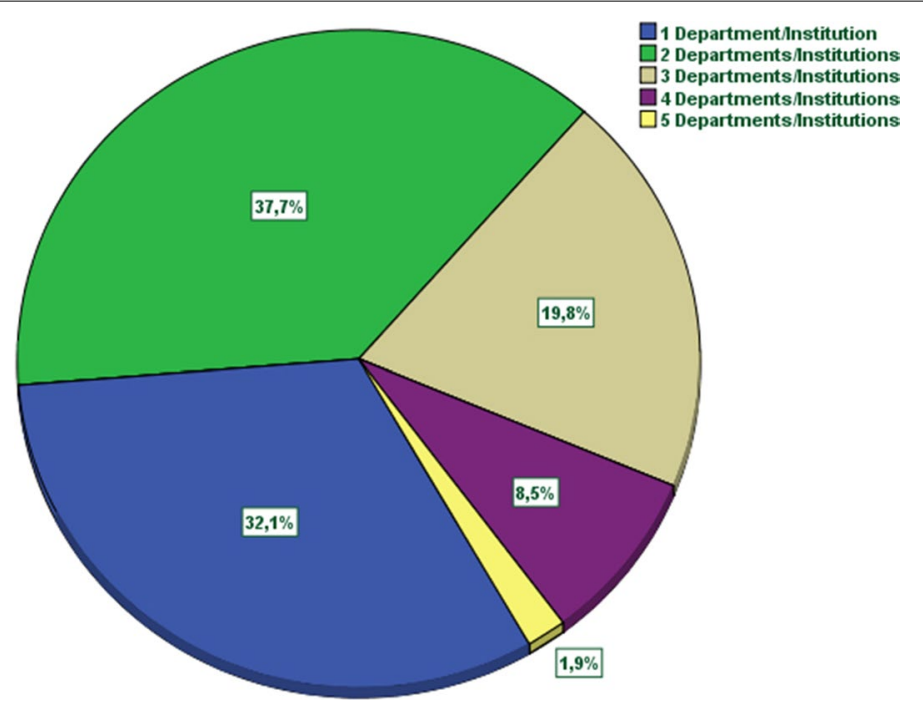

Fig. 5 Number or departments/institutions focused on different areas involved in the research

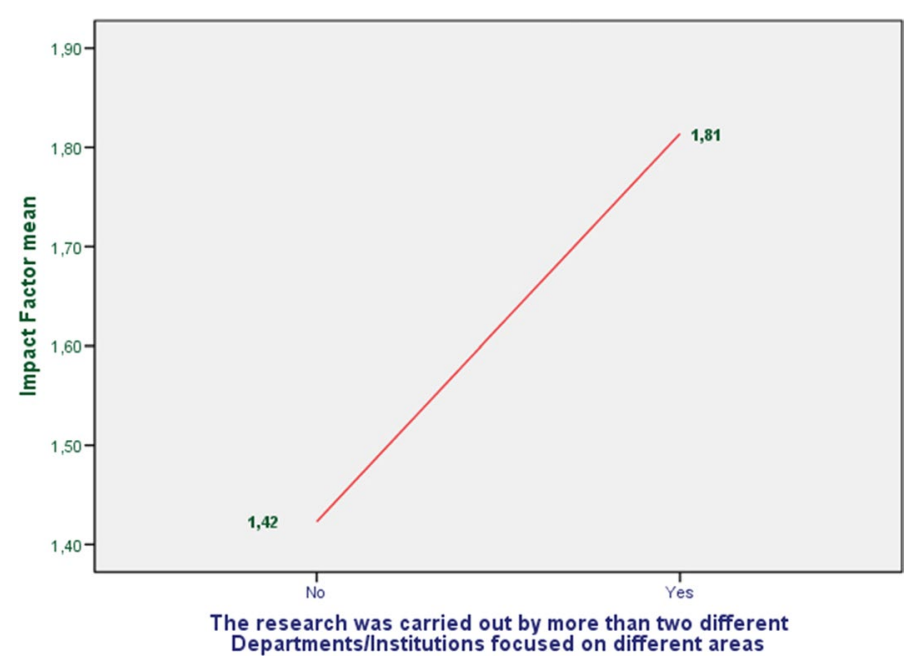

Fig. 6 Relation between teams of more than 2 different departments/institutions focused on different areas and impact factor

significant $(\mathrm{p}=0.33)$, obtaining an average impact factor of $1.81( \pm 1.93)$ for researches carried out by more than two teams focusing on different fields, versus $1.42( \pm 1.88)$ for teams with two or fewer different fields of knowledge. However, we evidenced a light but positive and significant relation between the Rao-Stirling diversity and the impact factor $(\mathrm{r}=0.182 ; \mathrm{p}=0.031)$ which means that a higher degree of interdisciplinarity increase of impact factor of the paper. Anyway, as we mentioned above, it is important to remember that the participation of multidisciplinary research teams does not necessarily means the presence of interdisciplinarity. This fact is supported by the analysis of the relation between the number of departments focused on different research areas for each paper and the value of Rao-Stirling diversity. In this case, we can not assume that the participation of research teams from different fields lead performing a multidisciplinary study. $(\mathrm{p}=0.108)($ see Fig. 7$)$. 


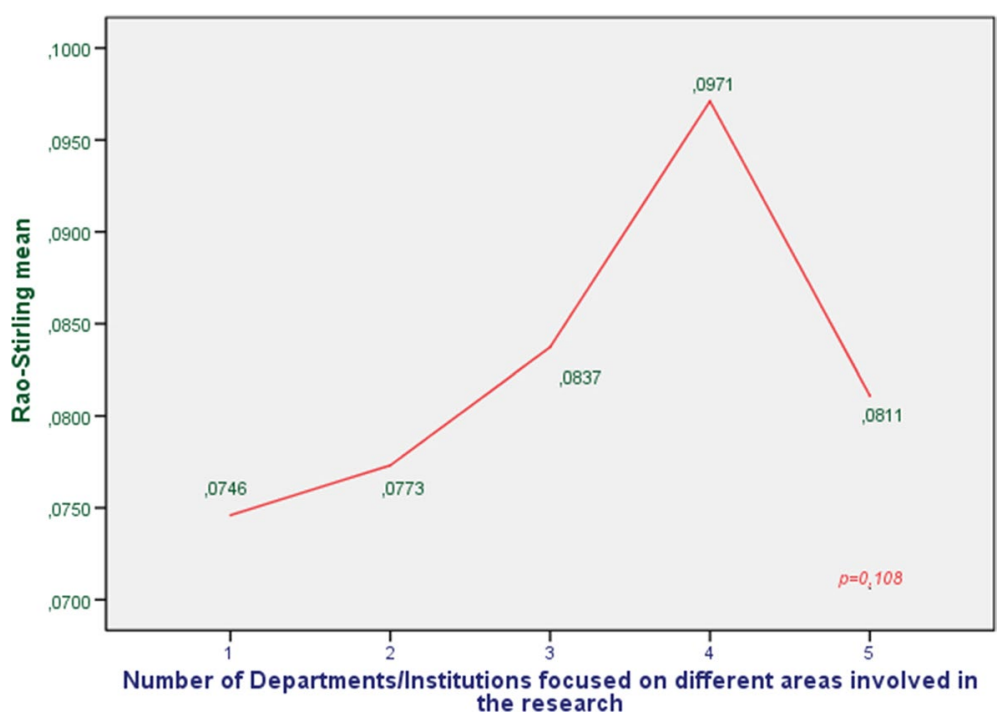

Fig. 7 Relation between number of departments/institutions involved in the research and Rao-Stirling diversity

Another method to evaluate the impact of a paper consists in evaluating the number of citations received. Neither the Rao-Stirling $(\mathrm{p}=0.063)$, the field where the publishing journal is classified according to 22 ISI web of knowledge categories $(\mathrm{p}=0.811)$, or the number of departments focused on different fields of knowledge $(\mathrm{p}=0.869)$, seem to be related to the number of citations received. The average number of citations for teams with more than two departments focused on different fields of knowledge is $6.52( \pm 9.9)$, versus an average of $6.14( \pm 9.6)$ citations for teams composed of two or less. From our point of view, this could be explained by the novelty of the research on mHealth, which seems to take precedence over the quality or focus of each investigation. We think that this could be also confirmed by the absence of statistical relations between the impact factor of the journals in which the papers were published, the number of citations received and the research design. That is, it would be logical to think that clinical trials, technological developments, and other quasi-experimental studies with higher levels of evidence, should be published in major journals or be more referenced. However, the result described above, indicates that this type of research designs is not better valued by publishers or other research investigators than others with lower levels of evidence (descriptive studies, qualitative researches, etc.).

A priori, it would seem that the interdisciplinary nature of the research teams is directly linked with access to publication in journals indexed in higher quartiles. This fact is confirmed by finding significant relations $(\mathrm{p}=0.027)$ between the quartile of the journal in which the articles were published and the number of departments focused on different areas involved in the investigation (see Fig. 8). By contrast, we did not find relation with Rao-Stirling diversity $(\mathrm{p}=0.475)$; showing that the fact of accessing higher quartiles may be related to the presence of multidisciplinary teams in the investigation, which does not necessarily mean that researches show an interdisciplinary approach. 


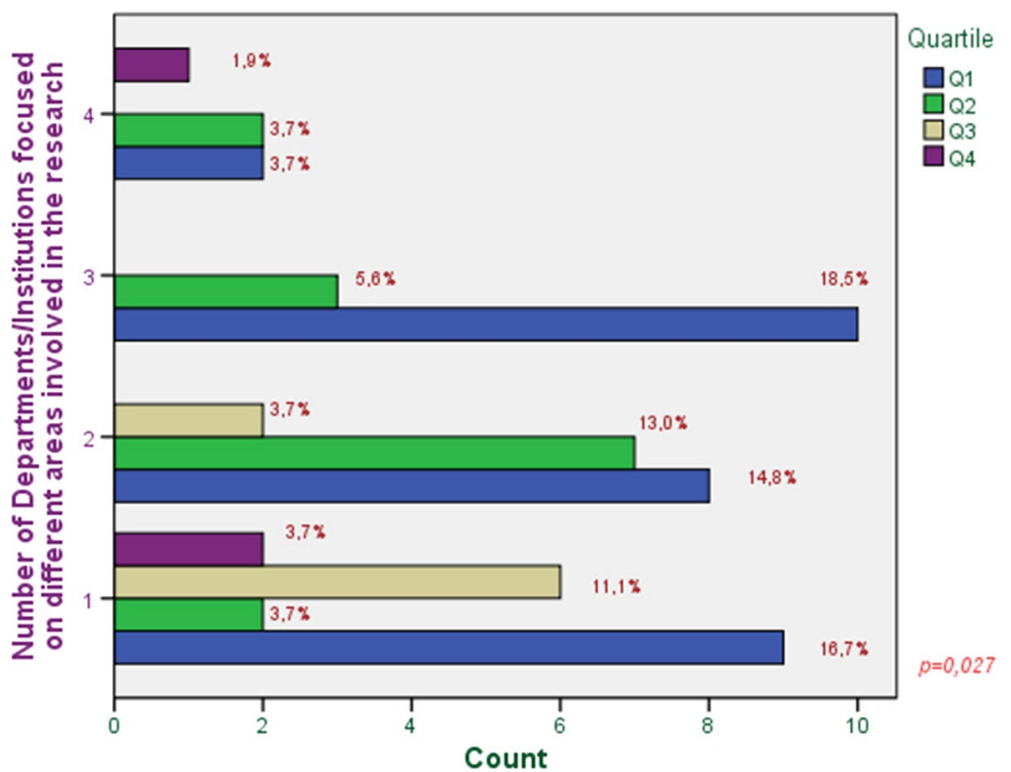

Fig. 8 Relation between the quartile of publication and the number of departments/institutions focused in different areas involved in the research

Another aspect to take into account is referent to the number of articles that are included in our study, which covers until October of 2015. Because of that, it is difficult to stablish the progression in the number of papers in this year. We considered that the number of papers in the last quarter of this year (2015) continue with a increasing tendency, but, it seems that in a lineal level (not exponential as in previous years). This fact could be only estimated in studies that will be carried out in 2016.

\section{Limitations}

The results should be taken with caution given various limitations. In this sense, Yadros et al. [6] stated some limitations as: "the inaccuracies in the WoS categories used to define subdisciplinary categories may create biases in the indicators of citation impact (since citation impact is highly affected by normalisation) and may have an important effect as well in diversity measures.", or "the inclusion or not of some control variables such as number of co-authors, institutions or article length is open to debate and these may have an effect on results., among others.

On the other hand, from the revised bibliography it is possible to extract that for calculating certain bibliometric indexes (as Rao-Stirling diversity), it is usual to consider a higher quantity of the number of papers than the number of them that we have considered in this work. This fact is because the main objective in our paper was to realize a systematic review and no the calculation of bibliometric indexes. The number of revised papers is considerably minor, so, it would be advisable to take with caution the results of this bibliometric index.

\section{Conclusions}

There are mHealth papers of all kinds (trials, analytical, descriptive, reviews, etc.) and its number grows at an exponential rate. This could show how technologies related to mHealth are reaching the scientific field. These technologies are reaching the population 
even faster. Therefore, mHealth is becoming an interesting research topic in both fields, health and computer sciences (hasta 2014 siendo más moderado en 2015).

These articles are published in high impact journals. We have found them in specific journals (focused on eHealth) and in generalist health and computing journals. Generalist journals have just begun to accept research based on the application of mHealth technologies. This highlights the growing importance of this topic.

There are already studies that warn of methodological deficits in some studies in mHealth, low accuracy and no reproducibility. Studies of low precision and poor reproducibility, coupled with the low evidence, provide low degrees of recommendation of the interventions targeted and therefore low applicability. The market apps, mostly lack of scientific evidence or participation of health professionals. This should compel publishers and researchers to be more stringent on the design of experiments and in the publication of results.

Fundamentally, it is possible to extract two main conclusions from our study. First, it is evident the increased interest that publishers of scientific journals are showing to mHealth, given the steady increase in publications focusing on this issue, regardless of the subject area. Second, it seems clear that the participation of multidisciplinary teams (with a variety of professionals focused on different areas of knowledge) is not necessarily linked to the presence of interdisciplinary approaches. Finally, this interdisciplinarity plays a limited role in the impact of the papers (measured by the impact factor of the journal where they are published and the number of citations that they received), this fact could be more related to the novelty of the topic of research.

Authors' contributions

All authors have equally contributed to the development of this work as well as the writing of this manuscript. All authors read and approved the final manuscript.

\section{Author details}

${ }^{1}$ Nursing Department, University of Córdoba, Córdoba, Spain. ${ }^{2}$ Area of Project Engineering, University of Córdoba, Córdoba, Spain.

\section{Competing interests}

The authors declare that they have no competing interests.

Declarations

Publication costs for this article were funded by University of Córdoba.

1. The App Date. Informe 50 Mejores Apps de Salud en Español. Madrid. 2014. http://www.theappdate.es/static/ media/uploads/2014/03/Informe-TAD-50-Mejores-Apps-de-Salud.pdf. Accessed 21 Dec 2015.

2. IMS Institute for Healthcare Informatics: patient adoption of mHealth: use, evidence and remaining barriers to mainstream acceptance. 2015

3. Deloitte Center for Health Solutions: mobilizing MedTech for mHealth: market trends and potential opportunities. 2015.

4. Economist The. Health 2.0: technology and society: is the outbreak of cancer videos, bulimia blogs and other forms of "user generated" medical information a healthy trend? Econ. 2007;6:73-4.

5. Giustini D. How Web 2.0 is changing medicine: editorial. Br Med J. 2006;333:1283-4.

6. Yegros-Yegros A, Rafols I, D'Este P. Does interdisciplinary research lead to higher citation impact? The different effect of proximal and distal interdisciplinarity. PLoS One. 2015;10(8):e0135095.

7. Molina-Recio G, García-Hernández L, et al. Impact of health apps in health and computer science publications. A systematic review from 2010 to 2014. Bioinformatics and biomedical engineering. Lecture notes in computer science. Berlin: Springer; 2015. p. 24-34.

8. Moher D, Liberati A, Tetzlaff J, Altman DG. The PRISMA Group. Preferred reporting items for systematic reviews and meta-analyses: the PRISMA statement. PLoS Med. 2009;6(6):e1000097. doi:10.1371/journal.pmed1000097.
} 
9. Rafols I, Meyer M. Diversity and network coherence as indicators of interdisciplinarity: case studies in bionanoscience. Scientometrics. 2010;82(2):263-87.

10. Porter AL, Roessner JD, Cohen AS, Perreault M. Interdiscipinary research: meaning, metrics and nurture. Res Eval. 2006;15:187-96.

11. IBM Corp. Released 2013. IBM SPSS Statistics for Windows, Version 22.0. Armonk: IBM Corp.

12. Liu C, Zhu Q, Holroyd KA, Seng EK. Status and trends of mobile-health applications for iOS devices: A developer's perspective. J Syst Softw. 2011;84(11):2022-33.

13. Cafazzo JA, Casselman M, Hamming N, Katzman DK, Palmert MR. Design of an mHealth app for the self-management of adolescent type 1 diabetes: a pilot study. J Med Internet Res. 2012;14(3):e70.

14. Hundert AS, Huguet A, McGrath PJ, Stinson JN, Wheaton M. Commercially available mobile phone headache diary apps: a systematic review. JMIR MHealth Uhealth. 2014;2(3):e36.

15. Wang A, An N, Lu X, Chen H, Li C, Levkoff S. A classification scheme for analyzing mobile apps used to prevent and manage disease in late life. JMIR MHealth Uhealth. 2014;2(1):e6.

16. Ploderer B, Smith W, Pearce J, Borland R. A mobile app offering distractions and tips to cope with cigarette craving: a qualitative study. JMIR MHealth Uhealth. 2014;2(2):e23.

17. Grindrod KA, Gates A, Dolovich L, Slavcev R, Drimmie R, Aghaei B, et al. ClereMed: lessons learned from a pilot study of a mobile screening tool to identify and support adults who have difficulty with medication labels. JMIR MHealth Uhealt. 2014;2(3):e35.

18. O'Malley G, Dowdall G, Burls A, Perry IJ, Curran N. Exploring the usability of a mobile app for adolescent obesity management. JMIR MHealth Uhealt. 2014;2(2):e29.

19. Dunford E, Trevena H, Goodsell C, Ng KH, Webster J, Millis A, et al. FoodSwitch: a mobile phone app to enable consumers to make healthier food choices and crowdsourcing of national food composition data. JMIR MHealth Uhealth. 2014;2(3):e37.

20. Pulman A, Taylor J, Galvin K, Masding M. Ideas and enhancements related to mobile applications to support type 1 diabetes. JMIR MHealth UHealth. 2013;1(2):e12.

21. Becker S, Miron-ShatzT, Schumacher N, Krocza J, Diamantidis C, Albrecht U-V. mHealth 2.0: experiences, possibilities, and perspectives. JMIR MHealth Uhealth. 2014;2(2):e24.

22. Lopez C, Ramirez DC, Valenzuela Jl, Arguello A, Saenz JP, Trujillo S, et al. Sexual and reproductive health for young adults in Colombia: teleconsultation using mobile devices. JMIR MHealth UHealth. 2014;2(3):e38.

23. Mann DM, Kudesia V, Reddy S, Weng M, Imler D, Quintiliani L. Development of DASH Mobile: a mHealth lifestyle change intervention for the management of hypertension. Stud Health Technol Inform. 2013;192:973.

24. Lyons EJ, Lewis ZH, Mayrsohn BG, Rowland JL. Behavior change techniques implemented in electronic lifestyle activity monitors: a systematic content analysis. J Med Internet Res. 2014;16(8):e192.

25. Iwaya LH, Gomes MA, Simplício MA, Carvalho TCMB, Dominicini CK, Sakuragui RRM, et al. Mobile health in emerging countries: a survey of research initiatives in Brazil. Int J Med Inf. 2013;82(5):283-98.

26. Lee SSS, Xin X, Lee WP, Sim EJ, Tan B, Bien MPG, et al. The feasibility of using SMS as a health survey tool: an exploratory study in patients with rheumatoid arthritis. Int J Med Inf. 2013;82(5):427-34.

27. Labrique A, Vasudevan L, Chang LW, Mehl G. Hope for mHealth: more "y" or "o" on the horizon? Int J Med Inf. 2013;82(5):467-9.

28. Alnanih R, Ormandjieva O, Radhakrishnan T. Context-based and rule-based adaptation of mobile user interfaces in mHealth. Procedia Comput Sci. 2013;21:390-7.

29. Menezes J Jr, Gusmão C, Machiavelli J. A proposal of mobile system to support scenario-based learning for health promotion. Procedia Technol. 2013;9:1142-8.

30. Sezgin E, Yıldırım SÖ. A literature review on attitudes of health professionals towards health information systems: from e-Health to m-Health. Procedia Technol. 2014;16:1317-26.

31. Van der Heijden M, Lucas PJF, Lijnse B, Heijdra YF, Schermer TRJ. An autonomous mobile system for the management of COPD. J Biomed Inform. 2013;46(3):458-69.

32. Balsam J, Rasooly R, Bruck HA, Rasooly A. Thousand-fold fluorescent signal amplification for mHealth diagnostics. Biosens Bioelectron. 2014;51:1-7.

33. Van Drongelen A, Boot CR, Hlobil H, Twisk JW, Smid T, van der Beek AJ. Evaluation of an mHealth intervention aiming to improve health-related behavior and sleep and reduce fatigue among airline pilots. Scand J Work Environ Health. 2014;40(6):557-68

34. Eskenazi B, Quirós-Alcalá L, Lipsitt JM, Wu LD, Kruger P, Ntimbane T, et al. mSpray: a mobile phone technology to improve malaria control efforts and monitor human exposure to malaria control pesticides in Limpopo, South Africa. Environ Int. 2014;68:219-26.

35. Hao W-R, Hsu Y-H, Chen K-C, Li H-C, labal U, Nguyen P-A, et al. LabPush: a pilot study of providing remote clinics with laboratory results via short message service (SMS) in Swaziland, Africa-a qualitative study. Comput Methods Programs Biomed. 2015;118(1):77-83.

36. Kuo M-C, Lu Y-C, Chang P. A newborn baby care support app and system for mHealth. Nurs Inform Proc Int Congr Nurs Inform. 2012;2012:228

37. Turner-McGrievy GM, Tate DF. Are we sure that mobile health is really mobile? An examination of mobile device use during two remotely-delivered weight loss interventions. Int J Med Inf. 2014;83(5):313-9.

38. King C, Hall J, Banda M, Beard J, Bird J, Kazembe P, et al. Electronic data capture in a rural African setting: evaluating experiences with different systems in Malawi. Glob Health Action. 2014;7:25878.

39. Bricker JB, Mull KE, Kientz JA, Vilardaga R, Mercer LD, Akioka KJ, et al. Randomized, controlled pilot trial of a smartphone app for smoking cessation using acceptance and commitment therapy. Drug Alcohol Depend. 2014; 143:87-94.

40. Jibb LA, Stevens BJ, Nathan PC, Seto E, Cafazzo JA, Stinson JN. A smartphone-based pain management app for adolescents with cancer: establishing system requirements and a pain care algorithm based on literature review, interviews, and consensus. JMIR Res Protoc. 2014;3(1):e15 
41. Ribu L, Holmen H, Torbjørnsen A, Wahl AK, Grøttland A, Småstuen MC, et al. Low- intensity self-management intervention for persons with type 2 diabetes using a mobile phone-based diabetes diary, with and without health counseling and motivational interviewing: protocol for a randomized controlled trial. JMIR Res Protoc. 2013;2(2):e34.

42. Brown W, Yen P-Y, Rojas M, Schnall R. Assessment of the health IT usability evaluation model (Health-ITUEM) for evaluating mobile health (mHealth) technology. J Biomed Inform. 2013;46(6):1080-7.

43. Balsam J, Bruck HA, Rasooly A. Capillary array waveguide amplified fluorescence detector for mHealth. Sens Actuators B Chem. 2013;186(7):11-7.

44. Akter S, D'Ambra J, Ray P. Development and validation of an instrument to measure user perceived service quality of mHealth. Inf Manag. 2013;50(4):181-95.

45. Datta AK, Sumargo A, Jackson V, Dey PP. mCHOIS: an application of mobile technology for childhood obesity surveillance. Procedia Comput Sci. 2011;5:653-60.

46. Surka S, Edirippulige S, Steyn K, Gaziano T, Puoane T, Levitt N. Evaluating the use of mobile phone technology to enhance cardiovascular disease screening by community health workers. Int J Med Inf. 2014;83(9):648-54.

47. Cornelius CT, Kotz DF. Recognizing whether sensors are on the same body. Pervasive Mob Comput. 2012;8(6):822-36.

48. Turner-McGrievy GM, Beets MW, Moore JB, Kaczynski AT, Barr-Anderson DJ, Tate DF. Comparison of traditional versus mobile app self-monitoring of physical activity and dietary intake among overweight adults participating in an mHealth weight loss program. J Am Med Inform Assoc JAMIA. 2013;20(3):513-8.

49. Kizakevich PN, Eckhoff R, Weger S, Weeks A, Brown J, Bryant S, et al. A personal health information toolkit for health intervention research. Stud Health Technol Inform. 2014;199:35-9.

50. Sunyaev A, Dehling T, Taylor PL, Mandl KD. Availability and quality of mobile health app privacy policies. J Am Med Inform Assoc JAMIA. 2015;22(e1):e28-33.

51. Martínez-Pérez B, de la Torre-Díez I, López-Coronado M, Herreros-González J. Mobile apps in cardiology: review. JMIR mhealth and uhealth. 2013;1 (2):e15.

52. Carter T, O'Neill S, Johns N, Brady RRW. Contemporary vascular smartphone medical applications. Ann Vasc Surg. 2013;27(6):804-9.

53. Abel O, Shatunov A, Jones AR, Andersen PM, Powell JF, Al-Chalabi A. Development of a smartphone app for a genetics website: the amyotrophic lateral sclerosis online genetics database (ALSOD). JMIR MHealth UHealth. 2013;1(2):e18.

54. Chen L, Wang W, Du X, Rao X, van Velthoven MH, Yang R, et al. Effectiveness of a smart phone app on improving immunization of children in rural Sichuan Province, China: study protocol for a paired cluster randomized controlled trial. BMC Public Health. 2014:14:262.

55. Bierbrier R, Lo V, Wu RC. Evaluation of the accuracy of smartphone medical calculation apps. J Med Internet Res. 2014;16(2):e32.

56. Brooke MJ, Thompson BM. Food and Drug Administration regulation of diabetes- related mHealth technologies. $J$ Diabetes Sci Technol. 2013;7(2):296-301.

57. Masters K. Health professionals as mobile content creators: teaching medical students to develop mHealth applications. Med Teach. 2014;36(10):883-9.

58. Parmanto B, Pramana G, Yu DX, Fairman AD, Dicianno BE, McCue MP. iMHere: a novel mHealth system for supporting self-care in management of complex and chronic conditions. JMIR MHealth UHealth. 2013;1 (2):e10.

59. Vriend I, Coehoorn I, Verhagen E. Implementation of an app-based neuromuscular training programme to prevent ankle sprains: a process evaluation using the RE- AIM Framework. Br J Sports Med. 2015;49(7):484-8.

60. Pérez-Cruzado D, Cuesta-Vargas Al. Improving adherence physical activity with a smartphone application based on adults with intellectual disabilities (APPCOID). BMC Public Health. 2013;13:1173.

61. Fiordelli M, Diviani N, Schulz PJ. Mapping mHealth research: a decade of evolution. J Med Internet Res. 2013;15(5):e95.

62. Lewis TL, Wyatt JC. mHealth and mobile medical apps: a framework to assess risk and promote safer use. J Med Internet Res. 2014;16(9):e210.

63. De la Vega R, Miró J. mHealth: a strategic field without a solid scientific soul. a systematic review of pain-related apps. PLoS One. 2014;9(7):e101312.

64. Shishido HY, de Alves da Cruz Andrade R, Eler GJ. mHealth data collector: an application to collect and report indicators for assessment of cardiometabolic risk. Stud Health Technol Inform. 2014;201:425-32.

65. Slaper MR, Conkol K. mHealth tools for the pediatric patient-centered medical home. Pediatr Ann. 2014:43(2):e39-43.

66. Martínez-Pérez B, de la Torre-Díez I, López-Coronado M, Sainz-De-Abajo B. Comparison of mobile apps for the leading causes of death among different income zones: a review of the literature and app stores. JMIR MHealth UHealth. 2014;2(1):e1.

67. Martínez-Pérez B, de la Torre-Díez I, López-Coronado M, Sainz-de-Abajo B, Robles M, García-Gómez JM. Mobile clinical decision support systems and applications: a literature and commercial review. J Med Syst. 2014;38(1):4.

68. Martínez-Pérez B, de la Torre-Díez I, López-Coronado M. Mobile health applications for the most prevalent conditions by the World Health Organization: review and analysis. J Med Internet Res. 2013;15(6):e120.

69. Yang YT, Silverman RD. Mobile health applications: the patchwork of legal and liability issues suggests strategies to improve oversight. Health Aff Proj Hope. 2014;33(2):222-7.

70. Boulos MNK, Brewer AC, Karimkhani C, Buller DB, Dellavalle RP. Mobile medical and health apps: state of the art, concerns, regulatory control and certification. Online J Public Health Inform. 2014;5(3):229.

71. Ahtinen A, Mattila E, Välkkynen P, Kaipainen K, Vanhala T, Ermes M, et al. Mobile mental wellness training for stress management: feasibility and design implications based on a one-month field study. JMIR MHealth UHealth. 2013;1(2):e11.

72. Barwais FA, Cuddihy TF, Tomson LM. Physical activity, sedentary behavior and total wellness changes among sedentary adults: a 4-week randomized controlled trial. Health Qual Life Outcomes. 2013;11:183. 
73. Tsui I, Drexler A, Stanton AL, Kageyama J, Ngo E, Straatsma BR. Pilot study using mobile health to coordinate the diabetic patient, diabetologist, and ophthalmologist. J Diabetes Sci Technol. 2014;8(4):845-9.

74. Goldenberg T, McDougal SJ, Sullivan PS, Stekler JD, Stephenson R. Preferences for a Mobile HIV prevention app for men who have sex with men. JMIR MHealth UHealth. 2014;2(4):e47.

75. Mobasheri MH, Johnston M, King D, Leff D, Thiruchelvam P, Darzi A. Smartphone breast applications—what's the evidence? Breast Edinb Scotl. 2014;23(5):683-9.

76. Zmily A, Mowafi Y, Mashal E. Study of the usability of spaced retrieval exercise using mobile devices for Alzheimer's disease rehabilitation. JMIR MHealth Uhealth. 2014;2(3):e31.

77. Mirkovic J, Kaufman DR, Ruland CM. Supporting cancer patients in illness management: usability evaluation of a mobile app. JMIR MHealth Uhealth. 2014;2(3):e33.

78. Klonoff DC. The current status of mHealth for diabetes: will it be the next big thing? J Diabetes Sci Technol. 2013;7(3):749-58.

79. Van der Weegen $\mathrm{S}$, Verwey $\mathrm{R}$, Spreeuwenberg $\mathrm{M}$, Tange $\mathrm{H}$, van der Weijden $\mathrm{T}$, de Witte $\mathrm{L}$. The development of a mobile monitoring and feedback tool to stimulate physical activity of people with a chronic disease in primary care: a user-centered design. JMIR MHealth UHealth. 2013;1 (2):e8.

80. Leal Neto OB, Albuquerque CM, Albuquerque JO, Barbosa CS. The schisto track: a system for gathering and monitoring epidemiological surveys by connecting geographical information systems in real time. JMIR MHealth Uhealth. 2014;2(1):e10

81. Albrecht U-V, Behrends M, Schmeer R, Matthies HK, von Jan U. Usage of multilingual mobile translation applications in clinical settings. JMIR MHealth UHealth. 2013;1(1):e4.

82. Hilliard ME, Hahn A, Ridge AK, Eakin MN, Riekert KA. User preferences and design recommendations for an mhealth app to promote cystic fibrosis self-management. JMIR MHealth UHealth. 2014;2(4):e44.

83. Arnhold M, Quade M, Kirch W. Mobile applications for diabetics: a systematic review and expert-based usability evaluation considering the special requirements of diabetes patients age 50 years or older. J Med Internet Res. 2014;16(4):e104.

84. Breton ER, Fuemmeler BF, Abroms LC. Weight loss-there is an app for that! But does it adhere to evidenceinformed practices? Transl Behav Med. 2011;1(4):523-9.

85. BinDhim NF, McGeechan K, Trevena L. Who uses smoking cessation apps? A feasibility study across three countries via smartphones. JMIR MHealth Uhealth. 2014;2(1):e4.

86. Breland JY, Yeh VM, Yu J. Adherence to evidence-based guidelines among diabetes self-management apps. Transl Behav Med. 2013;3(3):277-86.

87. Silva BM, Rodrigues JJPC, Canelo F, Lopes IC, Zhou L. A data encryption solution for mobile health apps in cooperation environments. J Med Internet Res. 2013;15(4):e66.

88. Mann DM, Quintiliani LM, Reddy S, Kitos NR, Weng M. Dietary approaches to stop hypertension: lessons learned from a case study on the development of an mhealth behavior change system. JMIR MHealth UHealth. 2014;2(4):e41.

89. Aguilera A, Schueller SM, Leykin Y. Daily mood ratings via text message as a proxy for clinic based depression assessment. J Affect Disord. 2015;175:471-4.

90. Almunawar MN, Anshari M, Younis MZ. Incorporating customer empowerment in mobile health. Health Policy Technol. 2015;4(4):312-9.

91. Anwar M, Joshi J, Tan J. Anytime, anywhere access to secure, privacy-aware healthcare services: issues, approaches and challenges. Health Policy Technol. 2015;4(4):299-311.

92. Azzazy HME, Elbehery AHA. Clinical laboratory data: acquire, analyze, communicate, liberate. Clin Chim Acta. 2015;438:186-94

93. Boissin C, Laflamme L, Wallis L, Fleming J, Hasselberg M. Photograph-based diagnosis of burns in patients with dark-skin types: the importance of case and assessor characteristics. Burns. 2015:41(6):1253-60.

94. Bradway M, Årsand E, Grøttland A. Mobile Health: empowering patients and driving change. Trends Endocrinol Metab. 2015;26(3):114-7.

95. Chang C-W, Ma T-Y, Choi M-S, Hsu Y-Y, Tsai Y-J, Hou T-W. Electronic personal maternity records: both web and smartphone services. Comput Methods Programs Biomed. 2015;121(1):49-58.

96. Danaher BG, Brendryen H, Seeley JR, Tyler MS, Woolley T. From black box to toolbox: outlining device functionality, engagement activities, and the pervasive information architecture of mHealth interventions. Internet Interv. 2015;2(1):91-101.

97. Green BB. BP here, there, and everywhere - mobile health applications (apps) and hypertension care. J Am Soc Hypertens. 2015;9(2):137-9.

98. Guo SH-M, Chang H-K, Lin C-Y. Impact of mobile diabetes self-care system on patients'knowledge, behavior and efficacy. Comput Ind. 2015;69:22-9.

99. Helf C, Hlavacs H. Apps for life change: critical review and solution directions. Entertainment Computing, 2015.

100. Jain N, Singh H, Koolwal GD, Kumar S, Gupta A. Opportunities and barriers in service delivery through mobile phones (mHealth) for Severe Mental IIInesses in Rajasthan, India: a multi-site study. Asian J Psychiatry. 2015;14:31-5.

101. Kramer GM, Kinn JT, Mishkind MC. Legal, regulatory, and risk management issues in the use of technology to deliver mental health care. Cogn Behav Pract. 2015;22(3):258-68.

102. Kumar N, Khunger M, Gupta A, Garg N. A content analysis of smartphone-based applications for hypertension management. J Am Soc Hypertens. 2015;9(2):130-6.

103. Lucivero F, Prainsack B. The lifestylisation of healthcare? 'Consumer genomics' and mobile health as technologies for healthy lifestyle. Appl Transl Gen. 2015;4:44-9.

104. Maciel FR, Hayashi S. NOPA, usability testing of an application to help patients during the treatment of infectious, and chronic diseases in Brazil. Procedia Manufacturing. 2015;3:6388-92. 
105. McCarroll ML, Armbruster S, Pohle-Krauza RJ, Lyzen AM, Min S, Nash DW, Roulette GD, Andrews SJ, von Gruenigen $V E$. Feasibility of a lifestyle intervention for overweight/obese endometrial and breast cancer survivors using an interactive mobile application. Gynecol Oncol. 2015;137(3):508-15.

106. Nocum AA, Baltao JM, Agustin DR, Portus AJ. Ergonomic evaluation and design of a mobile application for maternal and infant health for smartphone users among lower-income class filipinos. Procedia Manufacturing 2015;3:5411-8.

107. Nunes IL, Simões-Marques MJ. Exploiting the Potential and Facing the Challenges of Mobile Devices: application Examples. Procedia Manufacturing. 2015;3:807-14.

108. Olla P, Tan J, Kauniskangas H. BPH laboratories: a proof-of-concept case on integrating smartphone diagnostics into clinical systems. Health Policy Technol. 2015;4(4):337-47.

109. Ovbiagele B. Phone-based intervention under nurse guidance after stroke: concept for lowering blood pressure after stroke in Sub-Saharan Africa. J Stroke Cerebrovasc Dis. 2015;24(1):1-9.

110. Paschou M, Papadimitiriou C, Nodarakis N, Korezelidis K, Sakkopoulos E, Tsakalidis A. Enhanced healthcare personnel rostering solution using mobile technologies. J Syst Softw. 2015;100:44-53.

111. Patterson V, Singh M, Rajbhandari H, Vishnubhatla S. Validation of a phone app for epilepsy diagnosis in India and Nepal. Seizure. 2015;30:46-9.

112. Schnall R, rribarren SJ. Review and analysis of existing mobile phone applications for health care-associated infection prevention. Am J Infect Control. 2015;43(6):572-6.

113. Silva BMC, Rodrigues JJPC, de la Torre Díez I, López-Coronado M, Saleem M. Mobile-health: a review of current state in 2015. J Biomed Inform. 2015;56:265-72.

114. Sindi S, Calov E, Fokkens J, Ngandu T, Soininen H, Tuomilehto J, Kivipelto M. The CAIDE dementia risk score app: the development of an evidence-based mobile application to predict the risk of dementia. Alzheimer's Dement: Diagn, Assess Dis Monit. 2015;1(3):328-33.

115. Thompson MJ, Valdez RS. Online Filipino-Americans' perspectives on informatics-enabled health management. Health Policy Technol. 2015;4(4):320-36.

116. Waldman L, Stevens M. Sexual and reproductive health and rights and mHealth in policy and practice in South Africa. Reprod Health Matters. 2015;23(45):93-102.

117. Yang C-H, Maher JP, Conroy DE. Acceptability of mobile health interventions to reduce inactivity-related health risk in central Pennsylvania adults. Prev Med Rep. 2015;2:669-72.

Submit your next manuscript to BioMed Central and we will help you at every step:

- We accept pre-submission inquiries

- Our selector tool helps you to find the most relevant journal

- We provide round the clock customer support

- Convenient online submission

- Thorough peer review

- Inclusion in PubMed and all major indexing services

- Maximum visibility for your research

Submit your manuscript at www.biomedcentral.com/submit 